Acta Linguistica Hungarica, Vol. 52 (2-3), pp. 221-280 (2005)

\title{
WHOLE-PART AND PART-WHOLE INFERENCES IN GENERATIVE AND COGNITIVE LINGUISTICS*
}

\author{
ANDRÁS KERTÉSZ - CSILLA RÁKOSI
}

\begin{abstract}
The paper focuses on the relation between the analytical philosophy of science and modular and holistic approaches to cognitive linguistics, respectively. The authors show that Chomsky's as well as Bierwisch \& Lang's and Lakoff \& Johnson's approaches make substantial use of non-demonstrative inferences which the standard view of the analytical philosophy of science evaluates as fallacies. By outlining a metatheoretical framework focusing on plausible inferences, the authors argue that the inferences the theories mentioned make use of are plausible rather than fallacious. This finding illuminates basic aspects of theory formation in linguistics and motivates the revaluation of the methodological foundations of linguistic theories.
\end{abstract}

\begin{abstract}
"Zwischen der Philosophie und den Wissenschaften herrschen seit geraumer Zeit gestörte Verhältnisse; die Wissenschaftstheorie ist der moderne Versuch, sie wieder ins Reine zu bringen. Das findet in der Regel weder den Beifall der Wissenschaften, die ihren Abschied von der Philosophie als Abschied von einer spekulativen Vergangenheit zu stilisieren pflegen, noch den Beifall der Philosophie, sofern diese angesichts ihres reichen klassischen Erbes dazu neigt, der wissenschaftstheoretischen Askese philosophische Armut zu bescheinigen. [.. .] Gegen diese Auffassung wendet sich heute die Wissenschaftstheorie. In Form einer das wissenschaftliche Wissen analysierenden [...] Bemühung wird Wissenschaft wieder zu einem philosophischen Thema und Philosophie wieder zu einem Element wissenschaftlichen Selbstverständnisses."
\end{abstract}

(Mittelstraß 2004, 5-6; emphasis added)

\footnotetext{
* Work on the present paper was supported by the Research Group for Theoretical Linguistics of the Hungarian Academy of Sciences at the University of Debrecen. We are grateful to Péter Csatár (Debrecen), Verena Haser (Freiburg), Tamás Mihálydeák (Debrecen), Marina Rakova (St. Petersburg), Andreas Haupt (Jena) for helpful criticism. Our special thanks are due to Péter Pelyvás and George Seel for improving our English. We take sole responsibility for all mistakes and shortcomings.
} 


\section{Introduction ${ }^{1}$}

As Hilary Putnam showed in one of his seminal papers (Putnam 1962), however diverse the analytical philosophy of science in the first half of the twentieth century was, there was a set of assumptions which most approaches shared. Putnam called this set of assumptions the "received view" of the analytical philosophy of science. To put it in a very simplified manner, some basic characteristics of the latter can be summarized as follows:

(RV) The "received view" assumes, among other things, that

(a) scientific theories have to meet the standards of "rationality";

(b) scientific theories have to be "deductive", "empirical" and "explanatory"; and

(c) there is a clear distinction between the process of scientific discovery (called "the context of discovery") and the form in which the results of discovery, that is scientific theories, are presented (cf. "the context of justification"). ${ }^{2}$

It is the "received view" that has served as the basic methodological standard in mainstream theoretical linguistics since the late fifties (see e.g., Ringen 1975) and that has influenced the development of current theoretical linguistics to a substantial extent. The best-known example

${ }^{1}$ In the paper we will make extensive use of quotations. This is, admittedly, not a very elegant way of arguing. Nevertheless, quotations will serve three important purposes. Firstly, the scope of our paper does not permit a detailed presentation of the theories it focuses on. Therefore, quotations will document our claims concerning those aspects of the theories which are relevant from our point of view but which cannot be introduced systematically. In such cases the quotations will appear in the footnotes. Secondly, they simply summarize pieces of background information which we will have to make use of as relevant steps within our line of argumentation; in such cases they will be part of the main text. Thirdly, we will argue against deeply rooted prejudices which most theoretical linguists share and this undermines the picture most linguistic theories draw of themselves. This is, of course, a risky enterprise. Thus, the quotations also serve the legitimization of our approach in that they witness that our claims are well-motivated by the logical and argumentation-theoretical literature which, unfortunately, most linguists are not familiar with.

Let us also remark that the present paper focuses on a possible application of plausibility theory to the analysis of argumentation in linguistics. However, plausibility theory is characterized, among other things, by a very vague terminology (see also Walton 2001 on this). Therefore, basically we will use all notions preexplicatively.

${ }^{2}$ For a detailed discussion of the "received view" cf. Suppe (1977). 
of the impact of the "received view" on linguistics is, of course, generative grammar. However, the proponents of most current linguistic theories failed to notice the fact that the "received view" is anything but up to date. Although, as well-known developments in the philosophy of science witness, it has been "out" for several decades and no longer counts as a serious alternative to current trends, the majority of theoretical linguists still assumes its validity. For example, even the latest version of generative linguistics accepts the scientific standards of the received view. ${ }^{3}$ In this respect, the methodology of linguistics is far behind the current state of the art in the philosophy of science. This situation is especially interesting with respect to the so-called "cognitive turn" in linguistics. ${ }^{4}$

It is instructive to observe that proponents of dominating approaches to cognitive linguistics consider it important to characterize their approach by relating it to the "received view". Accordingly, this relation is treated as a relevant component of the definition of the approach at issue. Basically, there are two extreme attitudes. On the one hand, modular approaches to cognitive linguistics - for example Bierwisch and Lang's two-level model - explicitly conform to the analytical tradition and, what is more, consider this as a major achievement. ${ }^{5}$ In addition,

3 "[...] a 'naturalistic approach' to the mind investigates mental aspects of the world as we do any others, seeking to construct intelligible explanatory theories, with the hope of eventual integration with the 'core' natural sciences." (Chomsky 2000, 76; emphasis added)

${ }^{4}$ The notions "cognitive linguistics" and "cognitive semantics" will be used preexplicatively, too. For a possible explication of these notions, see Kertész (2004a).

${ }^{5}$ See the following quotation as an illustration:

"Was besagt die angedeutete Perspektive der kognitiven Wissenschaften für das Verständnis linguistischer Fragestellungen? Der entscheidende Punkt ist, daß die Linguistik von der im wesentlichen deskriptiven Analyse natürlicher Sprachen zur Formulierung erklärender Theorien über ihren Gegenstandsbereich gelangt. Dieser Übergang von einer beschreibenden zu einer erklärenden Wissenschaft ist ein fundamentaler Wechsel in der Orientierung, auch wenn er sich schrittweise und nicht immer leicht erkennbar vollzieht. Er verlangt die Aufdeckung und kontrollierbare Formulierung von Gesetzmäßigkeiten oder Prinzipien, denen die Sprachkenntnis unterliegt, aus denen also ihre charakteristischen Eigenschaften abgeleitet werden können. In dem Maß, in dem solche Gesetzmäßigkeiten formuliert und begründet werden können, wird die kognitiv orientierte Linguistik zu einer Disziplin, in der die in der Naturwissenschaft geltenden Grundsätze der Theoriebildung und Erklärung wirksam werden."

(Bierwisch 1987, 646; emphasis added) 
this assumed progress is claimed to be inseparable from the success of generative grammar. ${ }^{6}$ On the other hand, holistic approaches such as the "second generation cognitive science" advocated by Lakoff and Johnson's cognitive theory of metaphor fiercely reject the analytical standards of scientific theory formation. ${ }^{7}$ This rejection of analytical philosophy is, of course, accompanied by the rejection of generative grammar.

The fact that (i) the "received view" is an outworn conception within the philosophy of science and (ii) many current linguistic theories still accept it as a major methodological evaluation standard, suggests the question whether these linguistic theories really behave in the ways they declare. Do, for example, Chomsky's generative linguistics or Bierwisch and Lang's two-level approach really meet the standards of the so-called "received view" of the analytical philosophy of science, and, in turn, do Lakoff and Johnson or Langacker really follow a scientific attitude that radically differs from the methodology of the analytical tradition? This is the question which the present paper centres around. However, such a general and vaguely raised question is difficult to grasp. Therefore, so as to obtain a more precise and more specific problem whose discussion may lead to instructive findings, we will narrow it down in several respects.

Firstly, we will focus on the structure of inferences. The motivation for this decision is that the "received view" presupposes the rationality of scientific inquiry. Although within the analytical philosophy of science there are different views concerning the question of what rationality is, there seems to be agreement on the fact that one thing that rationality involves is that the theses of a theory must be connected by valid logical inferences, also known as demonstrative inferences. ${ }^{8}$ Consequently, whether cognitive linguistic theories conform to the analytical tradition

\footnotetext{
${ }^{6}$ For example:

"Es liegt mithin in der Natur der Sache, daß die Entwicklung der Linguistik als kognitive Wissenschaft nicht von der der generativen Grammatik zu trennen ist."

(Bierwisch 1987, 646)

7 "Philosophy is so much an implicit, though not always recognized, part of all intellectual disciplines that it has determined, for many investigators, the conception of what cognitive science is. There are at least two approaches to cognitive science defined by different philosophical commitments: a first-generation cognitive science that assumed most of the fundamental tenets of traditional Anglo-American philosophy and a second generation that called most of those tenets into question on empirical grounds." (Lakoff-Johnson 1999, 75)

${ }^{8}$ In accordance with the literature, we will treat the notions "demonstrative", "deductive" and "conclusive" as synonyms.
} 
or not, may be tested, among other things, by examining to what extent they make use of demonstrative inferences.

Secondly, since both modular and holistic approaches to cognitive linguistics define themselves relative to generative linguistics, we are justified in discussing the latter as well. Thus, we will examine three examples so as to give an idea of how inferences in cognitive linguistics work: Chomsky's generative linguistics, Bierwisch and Lang's two-level model as an example of modular cognitive linguistics compatible with generativism, and Lakoff and Johnson's cognitive theory of metaphor as an illustration of holistic cognitive linguistics which rejects generative grammar in particular and the analytical philosophy of science in general.

Thirdly, in order to make our argumentation even more specific, we will choose two problematic patterns of inference as instructive points of departure. In particular, we will analyze applications of part-whole and whole-part inferences. The question of how to reconstruct these patterns of inference is controversial (see, e.g., van Eemeren-Grootendorst 1994; Kienpointner 1992, 277ff.; Woods-Walton 1989; Walton 1996 on this problem). Nevertheless, for the present purposes and as a first approximation, the following simplified outline of their structure will be sufficient.

(1) Part-whole inference

Premises:
(a) $x$ is part of $y$
(b) $x$ has the property $P$
Conclusion:
(c) $y$ has the property $P$

(2) Whole-part inference

Premises:
(a) $x$ is part of $y$
(b) $y$ has the property $P$
Conclusion:
(c) $x$ has the property $P$

Now the question arises as to how the "received view" of the analytical philosophy of science evaluates part-whole and whole-part inferences. The reason the analysis of (1) and/or (2) may be instructive is that they are non-demonstrative inferences. In the case of demonstrative inferences 
it is impossible that the conclusion is false while the premises are true. Non-demonstrative inferences, however, do not guarantee the truth of the conclusion on the basis of the premises. It is either the case that the conclusion need not be true although the premises are true,${ }^{9}$ or the premises are uncertain themselves and therefore the conclusion is uncertain, too. ${ }^{10}$

As we have already indicated, the "received view" presupposes what Ralph H. Johnson calls "deductive chauvinism":

"[...] validity is made the standard against which arguments are to be measured. [...] a serious problem with this conception is the underlying assumption it makes about argumentation: that all argumentation is deductive in nature."

(Johnson 1995, 111; emphasis added)

Consequently, according to the "received view", all non-demonstrative inferences should be evaluated as fallacies. See, for example, the following definition of the notion of fallacy:

\footnotetext{
"An argument whose premises do not imply its conclusion is one whose conclusion could be false even if all of its premises are true. An argument that fails in this [...] way is said to be fallacious, or to be a fallacy." ${ }^{11}$

(Copi-Burgess-Jackson 1996, 96; emphasis as in the original and added)
}

Thus, from the fact that (i) (1) and (2) are non-demonstrative inferences and (ii) all non-demonstrative inferences are considered to be fallacies, it follows that these two patterns are to be considered as fallacious inferences, too. Therefore, according to the standards of rationality which the "received view" of the analytical philosophy of science assumes, they must not play a significant role in the structure of scientific theories.

However, what makes this finding especially interesting is that - as we will show in section 2-Chomsky's generative linguistics, Bierwisch and Lang's two-level approach and Lakoff and Johnson's cognitive theory of metaphor do make use of (1) and (2) irrespective of how these theories

${ }^{9}$ Let us illustrate this with respect to pattern (1). If (a) David Beckham's head is round, and (b) David Beckham's head is part of his body, then (c) David Beckham's body is round. Obviously, (a) and (b) are true, while (c) need not be true.

${ }^{10}$ Cf. for example shaded modus tollens in Tables 1 and 2 in section $\mathbf{3 . 5}$.

11 "This criterion, in effect, means that any argument that is not deductively valid [...] is a fallacious argument. It would mean, for example, that all arguments that are inductively strong but not deductively valid are fallacious. And it would mean that all arguments that have a weight of presumption in their favor, but are not deductively valid [...] arguments, are fallacious arguments." (Walton 1992a, 236) 
define their own relation to the "received view" of the analytical philosophy of science. This finding leads to a highly problematic conclusion. Namely, on the one hand, all of the three theories violate the commonly accepted standards of the "received view" of the analytical philosophy of science which during the past five decades or so have been used as the basic methodological evaluation standard of linguistic theories. That this is so is quite natural with respect to holistic cognitive linguistics, but definitively counterintuitive in the case of the other two theories. Since the latter implicitly presuppose the standards of rationality advocated by the "received view" of the analytical philosophy of science, it follows that they violate their own standards. Therefore, if we accept the principles of rationality that the "received view" of the analytical philosophy of science maintains, all three theories should be rejected. However, such a decision would be fatal, because it leads to destructive consequences: in fact, there is no doubt that all three theories are successful enterprises widely applied by scientific communities, although, of course, different ones. Thus we obtain a dilemma: ${ }^{12}$

(D) We either maintain three linguistic theories which seem to violate the commonly accepted standards of rationality in the sense of (RV), or we reject them, although they are workable and successful.

Accordingly, we may reduce the problem outlined to the following more specific one:

(P) How can the dilemma (D) be solved?

The aim of the paper is to give an answer to $(\mathrm{P})$ by arguing for the tenability of the hypothesis $(\mathrm{H})$ :

\footnotetext{
${ }^{12}$ In the present paper it would be beside the point to take sides between the three theories. We simply consider it to be a fact (in whatever sense) that all three theories are maintained by certain scientific communities and do not ask the question which of them is "better" or "true". Our task is to capture this fact, among others by trying to resolve (D), and not to compare the theories. Moreover, by "successful" and "workable" we mean the heuristic potential of theories: namely, their capability of solving the problems they tackle by using their own means and/or their capability of raising new problems which can be captured by the same means or which, alternatively, give rise to approaches going beyond the scope of the theory at issue.
} 
(H) (a) On the one hand, the account of inferences that the "received view" of the analytical philosophy of science presupposes can be replaced by another approach which considers (1) and (2) as legitimate tools of scientific theorizing.

(b) On the other hand, this approach does not result in the strict rejection of the standards of rationality in the sense of (RV); rather, it extends them in so far as it distinguishes between two kinds of non-demonstrative inferences, namely, plausible and fallacious ones.

We will proceed as follows. In section $\mathbf{2}$ we will briefly present a very simple analysis of the way basic notions of Chomsky's theory of language, the central empirical hypothesis of the two-level approach and that of the cognitive theory of metaphor can be inferred from the premises they assume via (1) and (2). In section 3 we will outline some of the main tenets of a theory of plausible reasoning. We will show that the difference between plausible inferences and fallacies is basically context-dependent: whereas plausible inferences are effective tools of scientific problem solving in a given context of argumentation, fallacies are ineffective or even destructive. Therefore, in section 4 we will argue that the application of (1) and (2) is effective in the context of the three theories at issue, and that, consequently, these patterns are not to be seen as fallacies, but rather, as plausible inferences fulfilling important heuristic functions. Finally, in section $\mathbf{5}$ the findings will be summarized and far reaching conclusions concerning the nature of theory formation in linguistics will be drawn.

Already at this point it should be clear for the reader that we will be discussing inferences not from the point of view of logic, but from that of argumentation theory.

\section{On the use of (1) and (2)}

\subsection{The problem}

So as to make our line of thought as clear as possible, we will subdivide our main problem (P) into a series of sub-problems corresponding to the steps we summarized at the end of the previous section. We expect that through solving these sub-problems eventually we will be capable of arriving at $(\mathrm{H})$. Accordingly, the first question we have to ask is this: 
(P1) Do Chomsky's generative linguistics, the two-level approach and Lakoff and Johnson' cognitive theory of metaphor make use of (1) and (2) $?^{13}$

\subsection{Generative linguistics}

In an ingenious paper Forrai puts forward the claim that Chomsky's philosophy of man is rooted in the notions of creativity, freedom and constraints (Forrai 1987, 50). ${ }^{14}$ This means that Chomsky considers man to act freely within the constraints of his biological constitution. Moreover, Chomsky infers basic claims of his theory of language from this view of man by the use of a specific kind of non-demonstrative inference:

"How does this view of human nature connect to the study of language? The connection might have been set up by Chomsky's definition of the subject of linguistics. Linguistics is assumed to be the science of the idealized native speaker's linguistic competence. This definition may give rise to a very special kind of analogical reasoning, which can be schematically described as follows: Premise 1: $P$ is a part of $w$. Premise 2: $w$ has the property $A$. Conclusion: $P$ has property $A_{1}$, which is similar to property $A$. It is a non-demonstrative inference from a property of the whole to the property of the part. Chomsky's definition of the subject of linguistics establishes whole-part relationship between man and his linguistic competence. As a result, it facilitates inference from the properties of human nature to the properties of linguistic competence. Consequently, ideas about human nature may infiltrate into linguistic theory. What I will try to show is that the birth of some of Chomsky's linguistic ideas might be explained in this way."

(Ibid.; emphasis added)

${ }^{13}$ We deliberately chose the examples to be discussed along the lines of the following considerations. Firstly, precise analyses of reasoning are highly complex and lengthy; therefore, to keep our own line of thought within the frames of the present paper, we chose very simple examples which serve illustrative purposes and are not claimed to be precise argumentation analyses. For detailed case studies of plausible reasoning in linguistics, see e.g., Kertész (2004b), KertészRákosi (2005a;b), Rákosi (2005). Secondly, it is also important to exemplify that the reasoning patterns we are examining can be used for very different purposes in the three theories - e.g., for connecting the philosophical foundations of a given theory with its central notions, or for inferring the main empirical hypothesis of the theory, or for carrying out analyses of linguistic data. In this respect, our examples are deliberately heterogeneous. Thirdly, contrasting the two-level approach and generative linguistics (which accept the modularity hypothesis) on the one hand with the cognitive theory of metaphor (which pleads for the holistic hypothesis) on the other hand, exemplifies that even opposing empirical hypotheses may be built on the same patterns of inference.

${ }^{14}$ Forrai's paper is also discussed in Kertész (2004b), although in a different metatheoretical framework. 
Obviously, the structure of this inference corresponds to (2). Forrai shows that the application of the non-demonstrative inference mentioned leads to a series of notions which are in the centre of Chomsky's theory of language. The reconstruction of this inference is as follows:

(3) Premises:

(a) Linguistic competence is part of human nature.

(b) Human nature has the property $P$.

Conclusion:

(c) Linguistic competence has the property $P^{\prime}$, where $P^{\prime}$ is similar to $P$ (or even identical with it).

Depending on what properties $P$ and $P^{\prime}$ stand for, a series of further inferences are carried out. Firstly, the property at issue is regularity. Accordingly, the particular inference is this:

(4) Premises:

(a) Linguistic competence is part of human nature.

(b) In human behaviour regularity prevails.

Conclusion:

(c) In linguistic competence regularity prevails.

Secondly, creativity is considered to be a major property of human nature as well as of linguistic competence. Now we can reconstruct the structure of the inference as follows:

(5) Premises:

(a) Linguistic competence is part of human nature.

(b) Creativity is a fundamental property of human nature.

Conclusion:

(c) Creativity is a fundamental property of linguistic competence.

Thirdly, since creativity presupposes rules, the following inference presents itself:

(6) Premises:

(a) Linguistic competence is part of human nature.

(b) Human nature is governed by rules. 
Conclusion:

(c) Linguistic competence is governed by rules.

The fourth case concerns constraints. That is:

(7) Premises:

(a) Linguistic competence is part of human nature.

(b) Human nature is characterized by biological constraints.

Conclusion:

(c) Linguistic competence is characterized by biological constraints.

Fifthly, the structure of the inference underlying Chomsky's views of language acquisition can be reconstructed in this way:

(8) Premises:

(a) Language acquisition is part of human nature.

(b) Human nature is characterized by the fact that man creates freely within the constraints of his biological nature.

Conclusion:

(c) Language acquisition is characterized by the fact that man creates freely within the constraints of his biological nature.

Finally, Forrai mentions the evaluation measure of grammars. The reconstruction of the inference Forrai refers to is as follows:

(9) Premises:

(a) Linguistic competence is part of human nature.

(b) Human nature is characterized by systematicity.

(c) Systematicity is similar to simplicity.

Conclusion:

(d) Linguistic competence is characterized by simplicity.

So, relying on Forrai's considerations, we have seen that some of the major ideas which govern Chomsky's theory of language can be reconstructed as the conclusions of whole-part inferences in the sense of (2).

However, the situation is more intricate than we have assumed so far. In particular, Forrai starts his paper with the remark that although Chomsky himself never appeals to his political views so as to justify his 
linguistic theory, it may be assumed that there is an indirect relationship between his political philosophy and his linguistic programme. In fact, it seems to be the case that both his linguistic and his political ideas are rooted in his views of man. That this assumption is not totally mistaken, can be documented by many passages in Chomsky's writings. For example, his reply to Mitsou Ronat's question concerning the relationship between his political and linguistic objectives is as follows:

"If there is a connection, it is on a rather abstract level. [...] There is no very direct connection between my political activities, writing and others, and the work bearing on language structure, though in some measure they perhaps derive from certain common assumptions and attitudes with regard to basic aspects of human nature." （Chomsky 1979, 3; emphasis added)

Interestingly enough, we may assume that this relation rests on a partwhole inference which is the inverse of the whole-part inference discussed so far and which corresponds to the pattern introduced in (1). That is, man is part of society and Chomsky infers basic properties of society from basic properties of human nature:

(10) Premises:
(a) Man is part of society.
(b) Man has the property $P$.

Conclusion:

(c) Society has the property $P^{\prime}$, where $P^{\prime}$ is similar to or identical with $P$.

This general pattern is realized in the following specific inferences:

(11) Premises:
(a) Man is part of society.
(b) Man is characterized by creativity.
Conclusion:

(c) Society is characterized by creativity.

(12) Premises:
(a) Man is part of society.
(b) Man is characterized by biological constraints.
Conclusion:

(c) Society is characterized by biological constraints. 
(13) Premises:

(a) Man is part of society.

(b) Man is characterized by freedom within constraints.

Conclusion:

(c) Society is characterized by freedom within constraints.

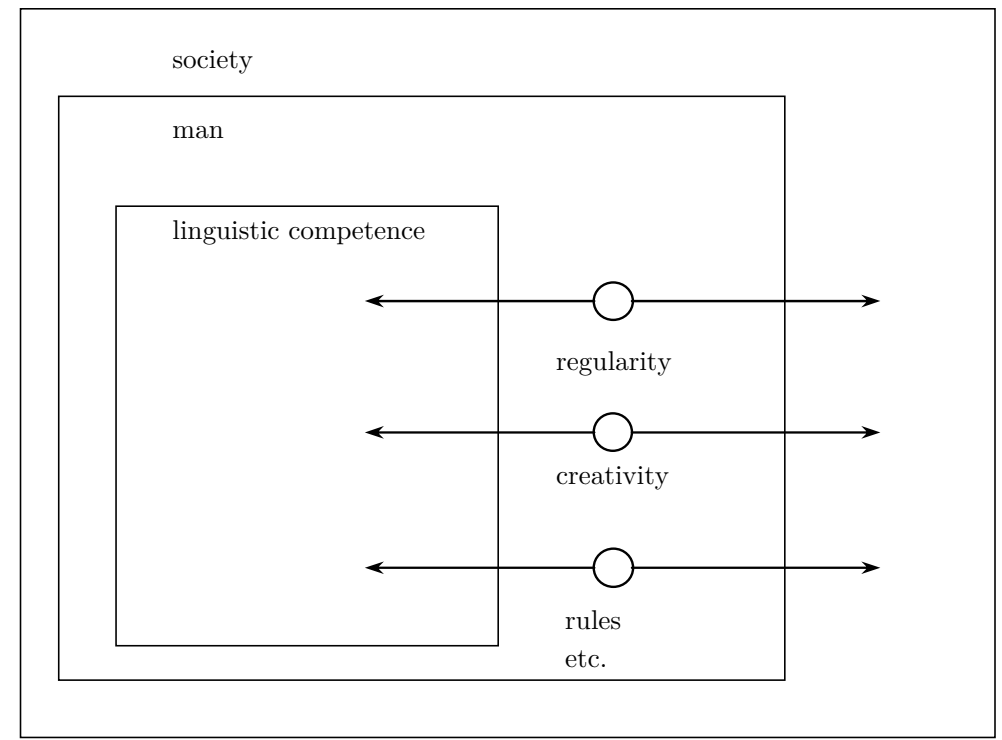

Fig. 1

In sum, we have seen two things. Firstly, Chomsky's views of man constitute the premises of two inferences pointing in opposite directions; the relationship between these two kinds of inferences is visualized in Figure 1. Secondly, both the philosophical foundations of his theory of language and his theory of society are closely related to the use of (1) and (2).

\subsection{The two-level approach}

The modularity hypothesis was introduced into linguistic theories in many different ways. The core of these diverse accounts is the following assumption:

(14) Knowledge of language is organized in a modular way. 
The relevance of (14) is rooted, among other things, in the fact that it constitutes one premise of the central argument for the assumption that cognition as a whole is modularly organized (see also Kertész 2004a). ${ }^{15}$ This inference leads to a very strong empirical hypothesis, but is, nevertheless, in most cases only applied implicitly. Then from (14) we can infer (15c) on the basis of (1):

(15) Premises:

(a) Knowledge of language is part of human cognitive behaviour.

(b) Knowledge of language is organized in a modular way.

${ }^{15}$ The argument, which leads from (14) to the modularity of cognition, is concisely summarized in the following quotation:

"Historisch gesehen, entwickelte sich die entscheidende Argumentation von der Autonomie zur Modularität. Chomsky zeigte zunächst, daß natürliche Sprachen über Eigenschaften verfügen, die ein Kind nur dann unter den üblichen Bedingungen erwerben kann, wenn bestimmte diesen Eigenschaften zugrundeliegende Prinzipien nicht erlernt werden müssen, sondern bereits in der Struktur des Kognitionssystems verankert sind [...]. Da diese Prinzipien in keiner erkennbaren Weise auf Prinzipien anderer kognitiver Bereiche, wie etwa Perzeption oder Begriffsbildung zurückgeführt werden können [...], müssen sie in ihrer sprachspezifischen Form kognitiv verankert sein. Wenn dies so ist, folgt logischerweise die Modularitätsthese, d.h. unser Kognitionssystem muß zumindest zwei autonome Module enthalten, und zwar das Grammatikmodul und ein Modul, das alle übrigen kognitiven Funktionen umfaßt. Da weiterhin Evidenz dafür vorliegt, daß auch für die (visuelle) Wahrnehmung ein eigenes autonomes Modul anzusetzen ist [...], gewinnt die Modularitätshypothese zunehmend an Plausibilität."

(Fanselow-Felix 1987, 174; emphasis added)

Fodor's (1983) argument seems to have a similar structure:

"Unabhängig von der Bewertung der einzelnen Beobachtung ist Fodor sicher zuzugestehen, daß er an einer Fülle von Beispielen erfolgreich demonstriert hat, daß perzeptuelle und sprachliche Prozesse im Kontext der Gesamtkognition des Menschen eine Sonderstellung einnehmen. Sie weisen Gesetzmäßigkeiten und Eigenschaften auf, die in anderen kognitiven Domänen nicht auftreten. Unter diesem Aspekt scheint die Auffassung eines globalen, alles umfassenden Kognitionssystems, das visuelle Perzeption und sprachliche Kodierung mit den gleichen Mechanismen und Strategien bewältigt wie das Lösen einer Mathematikaufgabe oder den Zusammenbau einer Maschine, wenig plausibel zu sein."

(Fanselow-Felix op.cit., 273)

Clearly, in both quotations the argument rests on a part-whole inference corresponding to (1) which is a frequently used problem-solving strategy in cognitive science.

Acta Linguistica Hungarica 52, 2005 
Conclusion:

(c) Human cognitive behaviour is organized in a modular way.

As illustrated in the last footnote, in the literature (15c) is inferred not only from (14) by using (1), but from (16) and (1) as well:

(16) Visual perception is organized in a modular way.

(15c) is the main empirical hypothesis of modularism in general and the two-level approach in particular. ${ }^{16}$ Nevertheless, Bierwisch and Lang use this conclusion as one of the premises of further inferences which are expected to yield the existence of specific autonomous subsystems. They focus on "semantic form" which is assumed to be the interface between the grammatical and the conceptual module. Thus they argue by making use of (2):

(17) Premises:

(a) The grammatical system/the conceptual system/semantic form is part of human cognitive behaviour.

(b) Human cognitive behaviour is organized in a modular way.

Conclusion:

(c) The grammatical system/the conceptual system/semantic form is organized in a modular way.

By way of summary, (1) and (2) constitute the means of inferring the central empirical hypotheses of the two-level-approach.

16 "Basically, all human cognitive behaviour is organized in a modular fashion. The structure formation underlying any concrete behaviour performance is based upon the integration of various relatively autonomous, task-specifically interacting systems and subsystems (MODULES). Language, the different modes of perception, and the conceptual organisation of experience make up such systems, which for their part are again structured in a modular way. The aim to be derived from this assumption is to identify systems, to analyze their structure and organisation in the attempt to capture the rationale behind their interaction." (Lang et al. 1991; emphasis added) 


\subsection{The cognitive theory of metaphor ${ }^{17}$}

Unlike (14), the holistic hypothesis assumes that knowledge of language cannot be subdivided into relatively autonomous systems and subsystems:

(18) Knowledge of language is a unified (holistic) system.

Among other things, holistic cognitive linguistics aims at the empirical reformulation, solution or elimination of classic philosophical questions concerning the nature of mind and knowledge (see e.g., Lakoff-Johnson 1999, 8). Against this background Lakoff and Johnson raise a series of classic philosophical problems to which they propose empirical solutions within the framework of their embodied realism. For example, they touch on the problem of Zeno's Arrow (Lakoff-Johnson op.cit., 157). As is well-known, the problem of the Arrow is rooted in Zeno's assumption according to which time is a sequence constituting a time line. Now, if we imagine the flight of an arrow, then at any point in time, the arrow is assumed to be at some fixed location. At a later point, its location is at another fixed point. That is, the arrow is located at a single fixed point each time. Thus, Zeno concludes that there is no motion and time is not divided up into instants.

In the light of this formulation, Zeno's classic standpoint is this:

(19) (a) Classic philosophical problem: Is there motion?

(b) Classic philosophical solution: There is no motion, because at any point of time the arrow is at some fixed location.

Lakoff and Johnson specify the task of their own version of cognitive linguistics as follows:

"The meaning of any philosophical question depends on what conceptual system is being used to comprehend the question. That is an empirical issue, an issue to be taken up by cognitive science in general and cognitive semantics in particular. [...] The same is the case for any proposed answer. An answer to a question like 'What is time?' is given relative to a philosophical conceptual system in which that answer is a meaningful answer. Such a philosophical conceptual system is part of the conceptual system of the philosophers doing the inquiry. The conceptual systems of philosophers are

${ }^{17}$ The following considerations are also discussed in Kertész (2004a) in a different context. 
no more consciously accessible than those of anyone else. To understand what counts as a meaningful answer, one must study the conceptual systems of the philosophers engaged in that inquiry. That too is an empirical question for cognitive science and cognitive semantics."

(op.cit., 136; italics as in the original and bold emphasis added)

The implicit argumentation underlying this quotation can be reconstructed in the following way:

(20) Premises:

(a) "a philosophical conceptual system is part of the conceptual system of the philosophers doing the inquiry," and

(b) the conceptual system of the philosophers doing the inquiry belongs to the subject matter of cognitive semantics.

Conclusion:

(c) A philosophical conceptual system belongs to the subject matter of cognitive semantics.

Lakoff and Johnson's solution to Zeno's problem uses a second inference as well:

(21) Premises:

(a) "a philosophical conceptual system is part of the conceptual system of the philosophers doing the inquiry,"

(b) the conceptual system of the philosophers doing the inquiry is a human conceptual system, and

(c) "the human conceptual system is metaphorically structured" (Lakoff-Johnson 1980, 6).

Conclusion:

(d) A philosophical conceptual system is metaphorically structured.

Thus, these inferences clearly rest on (2). From (20c) and (21d) it follows that it is the metaphorical structure of Zeno's conceptual system which is responsible for the problem of the Arrow. Therefore, this metaphorical structure needs to be revealed. The conceptual metaphor which is assumed to play a constitutive role in the structure of such a conceptual system is one that may be called the Moving Observer Metaphor (Lakoff - Johnson 1999, 146):

(22) LOCATIONS ON OBSERVER'S PATH OF MOTION ARE TIMES THE MOTION OF THE OBSERVER IS THE "PASSAGE" OF TIME

THE DistanCE MOVED By THE OBSERVER IS THE AMOUNT OF TIME "PASSED" 
This metaphor implies that "what we will encounter in the future is what we are moving towards", "what we are encountering now is what we are moving by", and "what we encountered in the past is what we moved past" (Lakoff-Johnson op.cit., 152). It is the identification of the Moving Observer Metaphor that yields the empirical solution to the problem of the Arrow. ${ }^{18}$

That is:

(23) (a) Empirical reformulation of the classic philosophical problem:

Is there motion, if

- there is a part in the brain that detects motion, and

- our motion detectors identify the arrow as moving?

(b) Empirical solution to the empirical problem:

There is motion, because

- our brains give us multiple ways of perceiving and conceptualizing the world and, within the latter, motion as well,

- we have a literal and a metaphorical way of conceptualizing motion,

- (19b) is false, because Zeno made the mistake of taking the Moving Observer metaphor to be literal.

18 " [...] In our terms, the idea that time is a linear sequence of points is metaphorical, a consequence of times seen as locations in the Moving Observer metaphor. The mistake, once again, is to take what is metaphorical as literal. Incidentally, a cognitive response to Zeno's paradox of the arrow is simple. There is a part of the brain that detects motion. Our motion detectors identify the arrow as moving. That is, our brains give us multiple ways of perceiving and conceptualizing the world. Motion is not a metaphorical concept. The idea that time a linear sequence of finite points is $[s i c]$. Our direct nonmetaphorically structured experience provides a simple response: Of course the arrow is moving. But in addition, we have an unconscious metaphorical conceptualization of instants of time as locations in space. We use this, for example, when we comprehend a picture of a moving object at a time: 'This is Sam driving by directly in front of our house at 10:06 p.m.' In other words, we have more than one way to conceptualize motion - one literal and one metaphorical. We can conceptualize motion directly, as when we think of Sam driving by and the hands of the clock moving. We can also conceptualize motion using a metaphorical conceptualization of time as a line with point locations on it. In the metaphor, and only in the metaphor, there is temporal location. Relative to the metaphor, we can fix a point location in time. Within the metaphor, at that point location, there can be no motion, since motion can only occur over regions of time in the metaphor. The appearance of paradox comes from attributing real existence to metaphorical point locations. Zeno's brilliance was to concoct an example that forced a contradiction upon us: literal motion and motion metaphorically conceptualized as a sequence of fixed locations at fixed points in time." (Lakoff-Johnson op.cit., 157-8; emphasis as in the original)

Acta Linguistica Hungarica 52, 2005 
Thus we have seen how the use of (2) facilitates the solution of a problem raised in Lakoff and Johnson's approach.

\subsection{Summary}

The considerations put forward and illustrated by the above examples boil down to the following claim to be considered as an auxiliary hypothesis which is the answer to (P1) and which corresponds to one of the stages in the argumentation whose result will be $(\mathrm{H})$ :

(H1) Chomsky's generative linguistics, the two-level approach and Lakoff and Johnson's theory do make use of (1) and (2).

As already mentioned, (H1) clearly motivates the dilemma (D) we raised in section 1. One way to handle (H1) would be, of course, to reject all of the three approaches, because they make substantial use of patterns of inference which the "received view" of the analytical philosophy of science considers to be invalid. Nevertheless, as we have mentioned, such a decision would be unreasonable, because it would lead to the rejection of theories which otherwise are undoubtedly workable and successful.

So, let us consider another possible solution already put forward in $(\mathrm{H})$ : namely, the claim that it is not the theories at issue which are illegitimate, but rather, it is the principles of rationality presupposed by the "received view" of the analytical philosophy of science that may be questioned. This second way of treating the problem is not unmotivated at all: in fact, recent investigations into the nature of scientific inquiry have shown that although strict logical validity may be a reasonable requirement in certain contexts, in many relevant cases it cannot be realized in scientific practice.

Accordingly, we will outline an approach whose aim is to capture certain aspects of this state of affairs. We will have to show three things:

(i) In contrast to (RV) (see section 1), not all non-demonstrative inferences are fallacies.

(ii) In the context of the theories at issue (1) and (2) are nonfallacious non-demonstrative inferences.

(iii) In particular, it is possible to distinguish between two sorts of non-demonstrative inferences, namely, plausible inferences and fallacies. 


\section{Preliminaries to a theory of plausible reasoning}

\subsection{The problem}

As is well known, the "received view" of the analytical philosophy of science maintains that the "context of discovery" - that is the process of problem solving - is beyond the scope of rationality and cannot therefore be captured by the philosophy of science (see (RVc)). In contrast, it is the "context of justification" - that is the reconstruction of the logical structure of well-developed theories - which constitutes the subject matter of the philosophy of science, because it is only the presentation of fully developed theories that is expected to follow the principles of rationality.

However, during the 1970's the distinction between the "context of discovery" and the "context of justification" was seriously questioned (Nickles 1980; 2001). The focus of interest changed gradually for philosophers of science: the processes of theory development also became an interesting research topic beside the justification of theories. In fact, the distinction between the two phases has been largely given up. This shift of emphasis had several independent sources.

Firstly, in many empirical disciplines the exposition of the results of research also reflects the way the corresponding problems were solved and remains strongly argumentative in nature. In this case very often even the final form in which the results are presented makes substantial use of non-demonstrative rather than demonstrative inferences. Mainly due to the pioneering work of Polya and Rescher, the assumption was formulated that in empirical disciplines it is plausibility considerations rather than strict logical validity that play a central role. Accordingly, the philosopher of science has to go beyond those purely formal considerations which demonstrative inferences permit and enter the realm of plausible reasoning.

Secondly, the role which inconsistency plays in scientific inquiry was acknowledged. From the seventies on different attempts to handle inconsistency by developing different approaches to paraconsistent logics were made (for recent overviews, see e.g., Meheus 2002 and Bremer 2005).

Thirdly, the development of artificial intelligence research gave rise to views which considered scientific inquiry as a process of problem-solving to be modelled by heuristics based on computer programmes.

In spite of the fact that these tendencies emerged independently of each other, they point in the same direction: some basic tenets of the "received view" of the analytical philosophy of science with respect to in- 
ferences in scientific theories are no longer acceptable. The central notions which may outline a new perspective are "problem solving", "discovery", "plausible inferences" and "inconsistency". On this background, it is fully legitimate to hypothesize that it is plausible inferences that might provide us the key to capturing these phenomena.

Although the pioneering activity of George Polya and Nicholas Rescher showed convincingly the relevance of plausible inferences and revealed basic aspects of their structure and functioning, and although these achievements have been unquestionably acknowledged, the individual sciences have not paid as much attention to them as they deserve: ${ }^{19}$

\footnotetext{
"Plausible reasoning is pervasive in daily life as well as in scientific activity. While inductive reasoning and probabilistic thinking have been the object of much interest among psychologists for a long time, the frequent case where people process uncertain premises and draw an uncertain conclusion [...] has remained relatively neglected. This is so despite the recognition of its importance by logicians and mathematicians [...] (Rescher 1976) and by philosophers [...] and the development of non-monotonic reasoning formalisms in Artificial Intelligence." (Politzer-Bourmaud 2002, 346; emphasis added)
}

According to the literature, non-demonstrative inferences include, for instance, inductive, analogical, abductive, defeasible, presumptive and plausible inferences. However, there is no generally accepted interpretation of these terms. This results in a kind of terminological vagueness which we have to live with. For example, in certain cases the term "plausible inferences" is treated as the genus proximum of inductive, analogical and other sorts of non-demonstrative inferences and excludes only fallacies from plausible reasoning. In other cases plausible inferences are considered to form a special class within non-demonstrative inferences as alternatives to inductive, analogical and abductive inferences. Following Polya and Rescher, we will maintain the standpoint mentioned first. ${ }^{20}$ Since the scope of the present paper does not permit the discussion of the arguments for this decision, let us mention that D. Walton, J. R. Josephson and S. G. Josephson seem to argue for the same view as well. ${ }^{21}$

In what follows we will show that Polya's and Rescher's ideas can be developed into a coherent approach to plausible inferences and fallacies

\footnotetext{
${ }^{19}$ Although Polya's and Rescher's ideas were published a couple of decades ago, they are still up to date. See e.g., Woods et al. (2000, 258), Walton (2001; 1992b), Chesñevar et al. (2000), etc.

${ }^{20}$ Cf. Polya (1954, Preface), Rescher (1976).

${ }^{21}$ Cf. Walton (2001).
} 
which differs from the "received view" in several respects. So as to put forward our approach, we will focus on the following question:

(P2) What are plausible inferences, that is, how can they be distinguished from

(a) demonstrative inferences on the one hand,

and

(b) fallacies on the other hand?

It is worth illustrating the nature of the problem by an instructive example. Traditionally it is assumed that one of the classical fallacies is "affirming the consequent" which can be contrasted with the valid inference form of modus tollens on the left. The main difference between the two inference patterns, in this view, is that while modus tollens is deductively valid, the inference pattern on the right is invalid although it seems to be correct, because it resembles modus tollens.

\begin{tabular}{|c|c|}
\hline $\begin{array}{l}A \text { implies } B \\
B \text { false }\end{array}$ & $\begin{array}{l}A \text { implies } B \\
B \text { true }\end{array}$ \\
\hline 4 false & $A$ true \\
\hline
\end{tabular}

It is instructive to observe that the very same pattern on the right is considered by Polya $(1948,221)$ not as a fallacy, but as the paradigm example of plausible inferences called "reduction" which he treats as the simplest and most frequently used pattern of plausible reasoning. Let us compare the traditional characterization of the pattern on the right side of the above table with Polya's considerations: ${ }^{22}$

"[...] let us consider the 'modus tollens' of the 'hypothetical syllogism' [...]:

$$
\begin{aligned}
& A \text { implies } B \\
& B \text { false } \\
& \hline A \text { false }
\end{aligned}
$$

Even from a quite primitive standpoint, we can see various remarkable features in this pattern of reasoning: it is impersonal, universal, self-sufficient, and definitive. [...] Let us compare the pattern of demonstrative reasoning (the 'modus tollens') [...] with the pattern of plausible reasoning [...]:

${ }^{22}$ The situation is even more complex. For example, just to mention one aspect, because the pattern at issue is also held to be a typical example of abduction. We cannot go into a discussion of the relationship between abductive and plausible inferences. See Walton (2001) for a concise overview. 


\author{
$A$ implies $B$ \\ $B$ true \\ $A$ more credible
}

Between these two patterns, the 'demonstrative' and the 'plausible', there is a certain outward similarity. (The demonstrative is traditional, and the other has been fashioned after it, of course.) Yet let us compare them more thoroughly.

Both patterns have the same first premise

$$
A \text { implies } B
$$

The second premises

$$
B \text { false } \quad B \text { true }
$$

are just opposite, but they are equally clear and definite; they are on the same logical level. Yet there is a great difference between the two conclusions

$$
A \text { false } \quad A \text { more credible }
$$

[...] The conclusion of the demonstrative pattern is on the same level as the premises, but the conclusion of our pattern of plausible reasoning is of different nature, less sharp, less fully expressed."

(Polya 1954, 112-3; emphasis as in the original)

The comparison shows that Polya's (and following him, Rescher's) main idea is that although in certain non-demonstrative inferences it is not the case that the conclusion is true whenever the premises are true, the latter may contribute to the credibility of the former. That is, the pattern called "affirming the consequent" is traditionally considered as a fallacy, because it is deductively not valid. Polya claims that the same pattern leads to a credible conclusion and therefore, although not deductively valid, it is fully legitimate.

In a similar vein, Walton argues that purely formal considerations are not enough to differentiate between correct and fallacious arguments:

"Many of the so-called fallacies, on closer inspection, turn out to be instances of argumentation that are defeasible, or opinion-based cases of presumptive reasoning, but inherently reasonable." (Walton 1991, 216; emphasis added) 
Accordingly, if it is only the form of inferences that is focused on, then one excludes inferences from the legitimate tools of reasoning which are (in whatever sense) "inherently reasonable" in spite of being non-demonstrative. Therefore, one of the difficulties of answering the questions in (P2) is that the distinction between demonstrative, plausible and fallacious inferences cannot rest solely on the form of inferences. Consequently, in what follows we will show how (P2) can be solved if the examination of inferences is not restricted to their formal aspects.

\subsection{On (P2a): plausible and demonstrative inferences ${ }^{23}$}

Comparing the demonstrative inference with the plausible one mentioned in the last quotation by Polya, we may observe that while with demonstrative inferences the truth of the conclusion follows from the truth of the premises with certainty, the premises of plausible inferences contribute only to the credibility of the conclusion. That is, firstly, as opposed to the certainty of demonstrative inferences, plausible inferences are uncertain and fallible (Polya 1948, 221; Walton 2001, 159, etc.).

Secondly, demonstrative (i.e., logically valid) inferences cannot lead to knowledge that goes beyond the information content of the premises. In contrast to this, plausible inferences are frequently used effective tools of acquiring new knowledge in mathematics, scientific inquiry and everyday life (Polya ibid.), because their conclusion may contain information not included in the premises. ${ }^{24}$

Thirdly, this kind of effectivity is closely connected to their heuristic function. As is well-known, demonstrative inferences are not suitable for bringing about decisions between alternative solutions to a given problem

${ }^{23}$ For more detailed discussions of our approach to plausible inferences with special focus on inconsistency, see Kertész (2004b), Kertész - Rákosi (2005b), Rákosi (2005). The following considerations are a brief summary of section $\mathbf{2}$ in KertészRákosi (2005c).

${ }^{24}$ Cf. Ruzsa (2000, 17):

"Knowledge obtained by logical inference is only relatively new: it must have been hidden in the premises, because otherwise it could not be the strict logical consequence of our premises. [...] It is impossible to gain totally new knowledge by logical inference."

However, it is important to remark that although the information content of the conclusion of a demonstrative inference cannot go beyond that of the premises, it makes implicit information explicit. This is one of the reasons why demonstrative inferences may be used for the solution of problems. 
which mutually exclude each other, but each of which is motivated by certain considerations with respect to the information available. ${ }^{25}$ In this respect, too, they differ significantly from plausible inferences, because the latter help us make decisions between alternatives on the basis of plausibility considerations. Accordingly, plausible inferences contribute to the solution of the problems raised (Polya 1948, 102f; Polya 1954, 140f; Walton 2001, 164). ${ }^{26}$

Fourthly, they are dynamic, because the conclusion of a plausible inference changes monotonically whenever one of its premises changes monotonically, and because such a change is continuous as well (Polya 1954, 26, 41; cf. also Walton 2001, 161). Therefore, there is a close relationship between plausible and demonstrative inferences: ${ }^{27}$

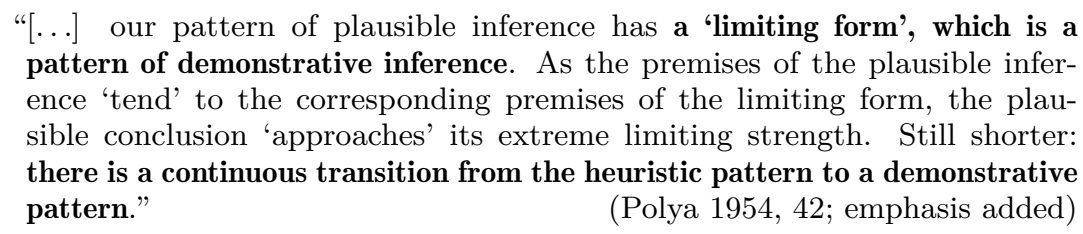

Fifthly, the premises of demonstrative inferences constitute a "complete basis", because "[i]f we receive some new information that does not change our belief in the premises, it cannot change our belief in the conclusion" (Polya 1948, 223). In contrast, the premises of plausible inferences make up only a "partial basis". This means that the complete basis has a part which is not expressed through the premises and which is, in this sense, "invisible". 28

${ }^{25}$ Cf. Rescher-Brandom (1979, 160).

${ }^{26}$ The most renowned Hungarian logician characterizes the nature of deductive logic as follows:

"Logic in most cases cannot provide an exhaustive answer to the question

'What conclusion can be drawn from it?,' as a certain aggregate of premises may support an infinite number of conclusions. What usually lies behind the question just quoted is the problem of what should be the next appropriate and desirable step during the relevant reasoning, demonstration or argumentation. Logic sometimes presents a basis for the answer, it delineates alternatives, but it cannot provide a universally valid method. It can only give an answer to the question of whether another proposition is a logical consequence of the given propositions or not." (Ruzsa 2000, 17; emphasis added)

${ }^{27}$ See Tables 1 and 2 in section $\mathbf{3 . 5}$ for illustrations.

${ }^{28}$ Let us illustrate this by a longer quotation, to which we will continuously refer in the sequel: 
Accordingly, sixthly, the conclusions of plausible inferences are context-dependent in a substantial and non-trivial way. The reason is that the credibility of conclusions cannot be established "absolutely", but depends significantly on the "strength" or "weight" (Polya's terms) of the premises. How credible a conclusion is can be judged only relative to the premises in particular and the properties of the partial basis in general (Polya 1954, 115f; Rescher 1976, 111ff; Walton 2001, 164).

Seventhly, while demonstrative inferences are formal in that they tell us that the conclusion is true if the premises are true, plausible inferences also take the content of the premises into consideration.

\subsection{On (P2b): plausible inferences and fallacies}

After we have differentiated between demonstrative and plausible inferences, the next question to be answered is how to distinguish between plausible inferences and fallacies, because both are non-demonstrative inferences. According to the classical view, a fallacious argument seems to be deductively valid whereas it is not (see e.g., Hamblin 1970, 224; cf. Woods-Walton 1989; Hansen-Pinto 1995). However, in the literature a couple of problems have arisen which undermine the acceptability of the classical view (see also van Eemeren-Grootendorst 2004, 158):

(i) In many cases the fallacy does not have a form which is similar to a valid inference pattern. For example, fallacies of the type "argumentum ad baculum" rely on the threatening of the opponent which is an ethical fault rather than a logical one.

"[...] the premises constitute only one part of the basis on which the
conclusion rests, the fully expressed, the 'visible' part of the basis; there
is an unexpressed, invisible part, formed by something else, by inartic-
ulate feelings perhaps, or by unstated reasons. In fact, it can happen
that we receive some new information that leaves our belief in both
premises completely intact, but influences the trust we put in $A$
in a way just opposite to that expressed in the conclusion. To find $A$
more plausible on the ground of the premises of our heuristic syllogism
is only reasonable. Yet tomorrow I may find grounds, not interfering at
all with these premises that make $A$ appear less plausible, or even de-
finitively refute it. The conclusion may be shaken and even overturned
completely by commotions in the invisible parts of its foundation, al-
though the premises, the visible part, stand quite firm." (Polya op.cit., 223f; emphasis added) 
(ii) In other cases the fallacy has a valid form. For example, the inference of the form " $A$, therefore $A$ " is trivially valid but commits the fallacy of petitio principii.

(iii) There is a large group of fallacies which contain a premise the acceptability of which can be questioned. For example, the fallacy "argumentum ad populum" relies on the argument that a statement is true because most people agree with it.

(iv) The classical view is too restrictive, because it considers nondemonstrative inferences as fallacies although both in scientific and everyday argumentation different kinds of non-demonstrative inferences are made use of.

Owing to these developments, the classical definition of "fallacy" has to be given up. There is wide agreement about this in argumentation theory; nevertheless, it is also clear that in connection with fallacies "most new theories are still in an embryotic stage, so it is too early to make any balanced judgements" (van Eemeren et al. 1996, 74). Therefore, we are in no position to find a satisfactory definition in the literature. Nevertheless, in the literature there are clear shifts of emphasis which we can use as points of departure.

Firstly, one of the objections raised against the classical definition of a fallacy is that " validity' is incorrectly presented as an absolute and conclusive criterion" (van Eemeren-Grootendorst 2004, 158). Correctness has a much wider scope than deductive validity, because not only deductive but other kinds of inferences may be correct in some sense as well: "[...] fallacy is an inference that falls short of some standard of correct inference (deductive, inductive, or whatever)" (Walton 1997, 212; emphasis added).

Secondly, in connection with this, what matters is not the valid vs. invalid form of an inference, but rather, the way a certain inference has been used in a given context of reasoning:

\footnotetext{
"If an argument is an instance of an invalid form of inference, it does not follow that the argument must be invalid. Whether the argument is fallacious or not depends on whether and how that form of inference has been used in the context of a dialogue."

(Walton op.cit., 213; emphasis added)
}

Thirdly, this kind of context-dependency of fallacies seems to be particularly interesting with respect to the fact that, as we have seen in the previous subsection, plausible inferences are context-dependent, too. Therefore, at this point we may refine the question asked at the beginning 
of the present subsection: How can we distinguish between plausible inferences and fallacies, if both are (a) non-demonstrative and (b) context dependent?

The answer seems to follow immediately from our approach to plausible inferences. As mentioned in the previous subsection, Polya considers plausible inferences to be indispensable heuristic tools of gaining new knowledge about the world. For Polya, the heuristic potential of inferences necessarily means their effectivity, or, to use an alternative expression in the same sense, constructivity: that is, their capability of bringing us nearer to the solution of a given problem in a given informational state. This boils down to the claim that the context-dependency of plausible inferences amounts to their effective use for the solution of the problems raised on the basis of the information available. Consequently, a fallacy arises if the use of a given pattern of inference is ineffective with respect to the heuristic tasks it is expected to fulfil. Thus, the answer to the question of how to draw the dividing line between plausible inferences and fallacies is that what primarily matters is effectivity: whereas plausible inferences are effective tools of acquiring new information in a certain context of argumentation, fallacies are ineffective and sometimes even destructive. This distinction is not specific to the framework we have outlined by relying on Polya's and Rescher's classical views. For example, van Eemeren and Grootendorst put forward a similar standpoint, although the argumentation theoretical framework they developed differs from ours:

$$
\begin{aligned}
& \text { "[...] fallacies are not 'absolute' mistakes that can simply be attributed to } \\
& \text { discussants by an analyst who penetrates the 'essence' of reasonableness, } \\
& \text { but moves in an argumentative discourse or text that can be characterized } \\
& \text { as less than constructive, or even destructive [...]." } \\
& \text { (van Eemeren-Grootendorst 2004, 175; emphasis added) }
\end{aligned}
$$

To avoid misunderstandings and unmotivated generalizations, at this point three remarks have to be made. The first is that effectivity in the sense just mentioned is not an absolute property of inferences. Even if in one context of reasoning an inference seems to be effective-because it appears to further the solution of some problem - in the light of new information, with respect to the new context thus modified it may turn out to be ineffective. Secondly, it is important to emphasize once more that the distinction we have just drawn reveals a shaded and subtle characterization of fallacies, but it does not provide us with a universal and in all situations clearly applicable criterion for judging whether a 
certain inference is fallacious or plausible. For example, an inference may have multiple effects: while it solves a particular problem, it may give rise to another one which perhaps cannot be solved on the basis of the information given. Or, it may generate a contradiction between such a solution and previously accepted theses of the theory which may either undermine the theory or, in contrast, further its development. Moreover, the evaluation of such reasoning itself is rooted in a partial basis, too. Accordingly, the evaluation of scientific reasoning itself is a process of plausible (meta)reasoning, which does not lead to final results, either. Rather, all this provides us only with fallible, uncertain findings which may seem plausible at a certain point of reasoning but can be rejected or revised in the light of later considerations. ${ }^{29}$ Thirdly, it is important to emphasize that although our approach shares many features with other approaches to argumentation theory, there are significant differences between our standpoint and that of other authors. ${ }^{30}$

${ }^{29}$ The notion of "context" within our approach to plausible reasoning will be explained in the next section.

${ }^{30}$ Without an attempt to present a detailed discussion of the literature, we only wish to indicate briefly in what aspects our approach is different from other standpoints.

For example, although in the present paper we have cited Walton approvingly several times and used quotations from his works to support our claims, there are also clear differences between our approach and his. To illustrate this, let us mention that Walton seems to agree with the "received view" of the analytical philosophy of science in so far as he accepts the substantial difference between "the context of discovery" and "the context of justification". This distinction is reflected in his view of the argumentation structure of these two phases of inquiry. He assumes that in "the context of discovery" the use of non-demonstrative inferences is permitted, whereas - because of their uncertainty - in the "context of justification" they must not be applied and only deductive and inductive inferences are justified (Walton 1992a, 207f; 2001, 157ff, 164f). Cf. Rákosi (2005) on this.

Or, to mention another example, we highly appreciate van Eemeren and Grootendorst's seminal contribution to argumentation theory and often agree with their conclusions. However, we do not share their idea that the analysis of fallacies should be based on normative models of argumentation which are nothing else but "well-defined systems of rules for the resolution of differences of opinion that the discussants intersubjectively accept" (cf. e.g., van EemerenGrootendorst 2004, 175).

From Polya's work our approach differs mainly in that we extend his basic ideas to the handling of inconsistency (Kertész-Rákosi 2005b) and fallacies. The main difference between Rescher's and our approach is that while Rescher focuses on plausibility metrics, our approach centres on patterns of plausible inference. 
What we have just said applies to (1) and (2) as well. They are nondemonstrative inferences which may be fallacious in one context, but correct in another: "Inference from a property of the part to a property of the whole is warranted only in some cases." (Walton 1997, 213) ${ }^{31}$

\subsection{On the epistemological framework of plausible reasoning}

The way plausible inferences work cannot be understood without outlining the overall epistemological framework which interprets the technique we sketched in sections $\mathbf{3 . 1}$ and $\mathbf{3 . 2}$.

Let us remember that plausible inferences are rooted in a partial basis. Starting from such a partial basis, we apply certain methods so as to arrive at new pieces of information, while we cannot make sure that the latter will really result in claims consistent with our initial assumptions. In such cases we reason cyclically. That is, we start off from a partial basis; then we return to the problems in question again and again, and supplementing the partial basis with different latent background assumptions we transform the set of information at our disposal by drawing additional plausible inferences, and re-evaluate the credibility of the respective hypotheses. During these cyclic returns we aim to filter out hypotheses unacceptable for some reason gradually, according to different - possibly contradictory - considerations (Rescher 1976, 111f, 118; Rescher 1987, 304). In this way it becomes possible to compare one's cycles and to assess one's progress.

From this starting point four very important consequences follow. The first is that, according both to Rescher and Polya, scientific inquiry proceeds not only cyclically, but also prismatically. This means that inasmuch as one tries to approach the given problem from several points of view during the cycles of reassessing what is known (Rescher 1987, 306f, 313; Polya 1981, 68), the cycles continuously change the point of view from which the information at our disposal is evaluated.

Secondly, due to its prismatic nature, the cyclic process of continuous retrospective revalidation does not yield vicious circularity, because cyclic reasoning never returns to the same stage. ${ }^{32}$

${ }^{31}$ Of course, the same applies to inferences from properties of the whole to properties of the part.

32 "The sort of 'self-criticism' at issue does not reflect any vicious or vitiating circularity, but in effect amounts simply to a feedback process that uses later, more 
The third consequence is that the cyclic and prismatic procedure of scientific inquiry can be best understood if we imagine it as a kind of double helix in the sense of Figure 2.33

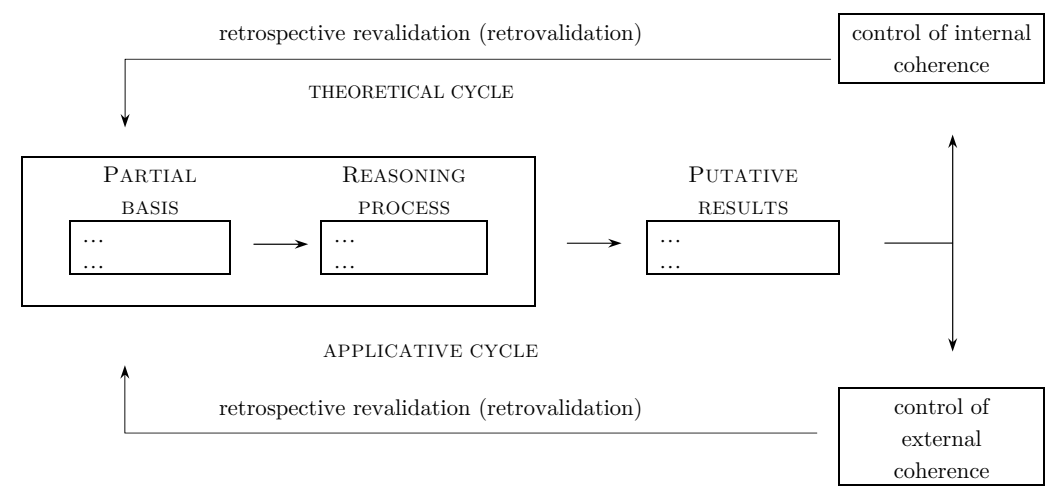

Fig. 2

Starting from the information in the partial basis one obtains new information by drawing plausible inferences. These results are, however, only putative, that is, their credibility has increased during the reasoning process, but they are still only plausible and not certain. Since consistency has to be established, it is unavoidable to control at least two things. First, whether the putative results are consistent with all the other claims in the partial basis of the theory (control of internal coherence). Second, it has to be checked, too, if the putative results are consistent with the "empirical" (whatever this term means) data (control of external coherence). If one or both of the two questions are answered negatively, it has to be decided - by the use of plausible inferences again - which parts of the basis have to be given up or modified and which further background assumptions should be added.

The aim of this cyclic and prismatic process of retrospective revalidation is primarily to rule out inconsistency and to arrive at a consistent set of assumptions. In this sense, the model we have just sketched, does not deny the basic values of rationality advocated by the "received view"

refined stages of the analysis to effect revisionary sophistications in the materials from which earlier stages proceeded. One indeed returns to 'the same point' but does so at a different cognitive level." (Rescher 1976, 119; emphasis as in the original and added)

${ }^{33}$ Figure 2 is based on suggestions in Rescher $(1977,122)$ and Rescher $(1979,103)$, but the terminology has been adapted to the notions we introduced in section $\mathbf{3 . 2}$. 
of the analytical philosophy of science; however, it considers them to be ideals which one should strive for but which normally cannot be realized. Thus, the fourth very important consequence of our approach to plausible reasoning is that scientific rationality must not be reduced to the use of demonstrative inferences; rather, it should be extended to capture plausible inferences as well. ${ }^{34}$ It does not follow from the fact that the conclusion of plausible inferences is not certainly true-but only credible, fallible, context-dependent - that plausible inferences are not rational. This highly important aspect of our model is, of course, in sharp contrast with the "received view" which restricts "rationality" to deductive inferences (and probabilistically based inductive inferences, at best). ${ }^{35}$

34 "But in going beyond the purely formal considerations of logic [...] plausibility theory does not go beyond the limits of rationality. [...] it aims at rational alignment and coordination of inferences." (Rescher 1976, 5; emphasis added)

${ }^{35}$ This attitude is expressively characterized by Walton:

"[...] it is very hard to get modern readers to come to accept plausible inference as having any hold on rational assent at all. We are so accustomed to the basing of our notion of rationality on knowledge and belief, we tend to automatically dismiss plausibility as 'subjective', and therefore of no worth as evidence of the kind required to rationally support a conclusion. The modern conventional wisdom is used to thinking of rationality as change of belief or knowledge guided by deductive reasoning and inductive probability. This modern way of thinking finds the notion of plausibility alien or even unintelligible, as an aspect of thinking."

(Walton 2001, 151)

Such an anachronistic attitude is one of the typical, unreflecting and outmoded methodological background assumptions underlying most linguistic theories, as already mentioned in section 1 . In fact, most mainstream linguistic theories presuppose the concept of rationality associated with the "received view", while in doing linguistics they make substantial use of plausible reasoning. That is, in so far as they declare to accept the standards of the "received view", they have to be evaluated as irrational by their own standards. Consequently, this seems to be a contradiction which they cannot resolve by their own means within their own framework. Therefore, in this respect, such theories - and, among them, all the stages of generative linguistics and the two-level approach - are essentially paraconsistent.

Nevertheless, the situation is, of course, much more complicated than the above quotation and our comment suggest. For example, the fact that plausible inferences may be considered to be rational, does not exclude the assumption that they correspond to different standards of rationality than deductive and inductive reasoning in scientific theories. Examining this problem would require a detailed comparison of Walton's, Rescher's and our view which would be beyond the limits of the present paper.

Acta Linguistica Hungarica 52, 2005 
Finally, let us - without defining it - explain in what sense in our framework the notion of "context" will be used. In accordance with Rescher and Polya, by "context" we will mean the whole of the information which is at one's disposal in a certain moment. In other words, the context includes all the hypotheses which seem to be plausible at a given stage of reasoning. This means that not only empirical hypotheses, but also background assumptions of other sorts such as methodological norms, patterns of inferences etc. are included in the context as well. Accordingly, in scientific theories the context changes continuously, because in the course of the cycles of reasoning one may obtain new information by the use of the method applied, or one may also give up some of the hypotheses accepted in one of the previous cycles, or one may assume new hypotheses, or the method can be changed, etc. For example, in Figure 2 the "context" of a certain assumption in the partial basis at a certain moment is the rest of the partial basis. Or, the context of the "putative results" includes the partial basis and the methods applied in this cycle - thus, in our case, the inferences (1) and (2). However, as soon as a cycle is closed, the context is supplemented by all the results provided by the whole cycle at issue. Because these results may contradict certain elements of the partial basis, it may be the case that one has to revaluate the hypotheses accepted previously. Accordingly, in this way the context may change again.

\subsection{Summary}

In section 3 we sketched an approach to plausible reasoning by distinguishing between three kinds of inferences: demonstrative, plausible and fallacious ones. This means that we argued for giving up the dichotomy "fallacy vs. demonstrative inference". See Figure 3 for this dichotomy.

\begin{tabular}{l|l} 
valid inferences & invalid inferences \\
\hline demonstrative inferences & $\begin{array}{l}\text { non-demonstrative inferences: } \\
- \text { plausible inferences } \\
\end{array}$ \\
\hline fallacies
\end{tabular}

Fig. 3

Rather, we suggested treating both demonstrative and plausible inferences as correct ones and assuming that non-demonstrative inferences 
consist of at least two subgroups, namely, fallacies and plausible inferences as illustrated in Figure 4.

\begin{tabular}{lllll}
\multicolumn{1}{c}{ correct inferences } & & incorrect inferences \\
\hline demonstrative & I & plausible & I & fallacies \\
inferences & I & inferences & I \\
& I & \multicolumn{2}{c}{ Fon-demonstrative inferences } \\
& \multicolumn{2}{c}{ Fig. }
\end{tabular}

Consequently, we may summarize our next auxiliary hypothesis as follows which is an answer to the question (P2):

(H2) (a) The distinction between demonstrative and non-demonstrative inferences rests on the certainty vs. uncertainty of the conclusion.

(b) Within non-demonstrative inferences, the distinction between plausible and fallacious inferences depends on the particular context of reasoning. The criterion is the effectivity of the inference within the context given.

However, the distinctions we have made do not mean that there is no link between these kinds of inferences:

(i) As we have shown in section 3.2, patterns of plausible reasoning can be seen as tending to the corresponding patterns of demonstrative inference when the credibility of the premises tends to certainty. As far as the premises of plausible inferences approach certainty, so, too, does their conclusion.

(ii) An analogous relation holds between plausible inferences and fallacies: the latter are nothing but plausible inferences deemed ineffective in a certain context of argumentation. If we give up the static view of fallacies that focuses on the form of inferences only, and try to consider the content of arguments by interpreting them dynamically, then fallacies are seen in a new light. They appear to be extreme cases on a scale: they are obtained from plausible inferences in that one moves towards contexts of argumentation in which these structures work less and less effectively.

In sum, we assume that reasoning centres on plausible inferences from which one can move towards two extremes: demonstrative and fallacious ones (Figure 5). From another point of view this means that, since the form of an inference itself does not decide whether it is plausible, demonstrative or fallacious, the dividing lines between these categories are not fixed either, but they are in constant motion depending on the particular context of reasoning. 


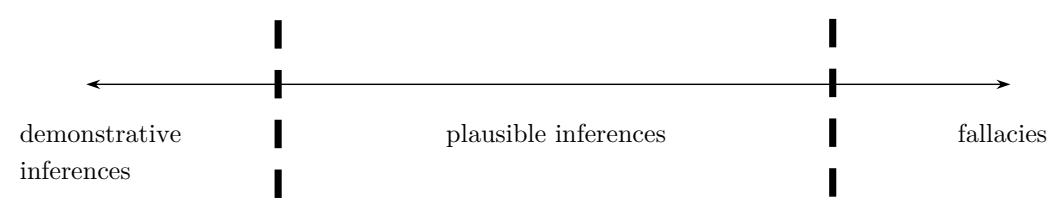

Fig. 5

Let us illuminate this system of inferences by two further remarks. Firstly, for example, modus tollens or modus ponens are demonstrative, if the premises are certain and, consequently, the conclusion is certain, too. We obtain, however, different cases of what Polya (1954, 23ff) calls shaded modus tollens or shaded modus ponens as soon as - while the form of the inference is the same - the premises and via the premises the conclusion, too, are not certain, but only credible to a particular degree. Furthermore, if for example a premise is held to be true although it is not because it overgeneralizes (i.e., when its plausibility is misjudged), ${ }^{36}$ then the conclusion will be faulty and the inference has to be evaluated as a fallacy. That is, the transition between these categories is clearly context-dependent, while plausible inferences can approach two extremes continuously. See Tables 1 and 2 (overleaf) as illustrations of the transition between the categories mentioned. ${ }^{37}$

Secondly, it is worth emphasizing that our model fits smoothly into current tendencies of inference research. For example, in summarizing the main findings of modern approaches to fallacies, Kienpointner emphasizes the following as one of the key points:

"Der Übergang von plausibler zur trugschlüssigen Argumentation ist graduel-
ler Natur, wobei für die entsprechende Einstufung von Argumentation stets
der [...] Kontext zu berücksichtigen ist. [...] Die Ermittlung von Trugschlüs-
sen ist nur im Rahmen einer umfassenden Theorie der 'fallacies' möglich, die
festlegt, was als 'fallacy' zählt und was nicht.” (Kienpointner 1992, 249-50)

Since many further aspects of Kienpointner's approach to plausible inferences differ substantially from Polya's, Rescher's and ours, the above statement serves as an independent argument for our model of fallacy.

${ }^{36}$ In section 4.4 we will discuss such a case.

${ }^{37}$ We have to remark three things. First, the second premise of each inference in the tables involves a comparison between the credibility of a piece of information ( $A$ resp. $B$ ) in a given moment and its credibility at a former informational state. Second, it is important to emphasize that there are many versions of each plausible inference pattern, because not only the second premise can be uncertain but the first one or both premises as well. Third, there are of course many different stages in the continuum and therefore, many different degrees of credibility/uncertainty. 
Table 1

\begin{tabular}{|c|c|c|c|c|}
\hline demonstrative & \multicolumn{2}{|c|}{ shaded plausible } & plausible & fallacy \\
\hline Premises: & Premises: & Premises: & Premises: & Premises: \\
\hline $\begin{array}{l}\text { It is certain } \\
\text { that if } A, \\
\text { then } B\end{array}$ & $\begin{array}{l}\text { It is certain } \\
\text { that if } A \text {, } \\
\text { then } B\end{array}$ & $\begin{array}{l}\text { It is certain } \\
\text { that if } A \text {, } \\
\text { then } B\end{array}$ & $\begin{array}{l}\text { It is certain } \\
\text { that if } A, \\
\text { then } B\end{array}$ & $\begin{array}{l}\text { It is certain } \\
\text { that if } A \text {, } \\
\text { then } B\end{array}$ \\
\hline $\begin{array}{l}B \text { is certainly } \\
\text { false }\end{array}$ & $\begin{array}{l}B \text { has become } \\
\text { less credible }\end{array}$ & $\begin{array}{l}B \text { has become } \\
\text { more credible }\end{array}$ & $\begin{array}{l}B \text { has turned out } \\
\text { to be true }\end{array}$ & $\begin{array}{l}B \text { is certainly } \\
\text { true }\end{array}$ \\
\hline Conclusion: & Conclusion: & Conclusion: & Conclusion: & Conclusion: \\
\hline $\begin{array}{l}A \text { is certainly } \\
\text { false }\end{array}$ & $\begin{array}{l}A \text { has become } \\
\text { less credible }\end{array}$ & $\begin{array}{l}A \text { has become some- } \\
\text { what more credible }\end{array}$ & $\begin{array}{l}A \text { has become } \\
\text { more credible }\end{array}$ & $\begin{array}{l}A \text { is certainly } \\
\text { true }\end{array}$ \\
\hline $\begin{array}{c}\text { modus } \\
\text { tollens }^{38}\end{array}$ & $\begin{array}{c}\text { shaded } \\
\text { modus tollens }\end{array}$ & $\begin{array}{l}\text { shaded } \\
\text { reduction }\end{array}$ & reduction & $\begin{array}{l}\text { affirming the } \\
\text { consequent }\end{array}$ \\
\hline
\end{tabular}

Table 2

\begin{tabular}{|c|c|c|c|c|}
\hline demonstrative & \multicolumn{2}{|c|}{ shaded plausible } & plausible & fallacy \\
\hline Premises: & Premises: & Premises: & Premises: & Premises: \\
\hline $\begin{array}{l}\text { It is certain } \\
\text { that if } A \text {, } \\
\text { then } B\end{array}$ & $\begin{array}{l}\text { It is certain } \\
\text { that if } A \text {, } \\
\text { then } B\end{array}$ & $\begin{array}{l}\text { It is certain } \\
\text { that if } A, \\
\text { then } B\end{array}$ & $\begin{array}{l}\text { It is certain } \\
\text { that if } A, \\
\text { then } B\end{array}$ & $\begin{array}{l}\text { It is certain } \\
\text { that if } A, \\
\text { then } B\end{array}$ \\
\hline $\begin{array}{l}A \text { is certainly } \\
\text { true }\end{array}$ & $\begin{array}{l}A \text { has become } \\
\text { more credible }\end{array}$ & $\begin{array}{l}A \text { has become } \\
\text { less credible }\end{array}$ & $\begin{array}{l}A \text { has turned out } \\
\text { to be false }\end{array}$ & $\begin{array}{l}A \text { is certainly } \\
\text { false }\end{array}$ \\
\hline Conclusion: & Conclusion: & Conclusion: & Conclusion: & Conclusion: \\
\hline $\begin{array}{l}B \text { is certainly } \\
\text { true }\end{array}$ & $\begin{array}{l}B \text { has become } \\
\text { more credible }\end{array}$ & $\begin{array}{l}B \text { has become some- } \\
\text { what less credible }\end{array}$ & $\begin{array}{l}B \text { has become } \\
\text { less credible }\end{array}$ & $\begin{array}{l}B \text { is certainly } \\
\text { false }\end{array}$ \\
\hline $\begin{array}{l}\text { modus } \\
\text { ponens }\end{array}$ & $\begin{array}{c}\text { shaded } \\
\text { modus ponens }\end{array}$ & $\begin{array}{l}\text { shaded refuting } \\
\text { the antecedent }\end{array}$ & $\begin{array}{l}\text { refuting the } \\
\text { antecedent }\end{array}$ & $\begin{array}{c}\text { denying the } \\
\text { antecedent }^{39}\end{array}$ \\
\hline
\end{tabular}

${ }^{38}$ One might ask why the premises and the conclusion claim the certainty of the propositions at issue. Firstly, the formal structure of modus tollens is of course $\{A \supset B ; \sim B\} \Rightarrow \sim A$. However, it is not sufficient to require formal validity only, because the inference has to be sound, too: "When an argument is valid, and all of its premises are true, we call it sound. The conclusion of a sound argument obviously must be true" (Copi-Burgess-Jackson 1996, 56). This means that (formal) validity alone is not enough to establish the truth of the conclusiontherefore, soundness, in other words, the certainty of the premises is required.

Secondly, we must not forget that we are discussing inferences not (to quote Quine) "from a logical point of view," but rather, from an argumentation theoretical point of view. That is, what we are focussing on is not pure logic, but reasoning which involves, among others, the way logic is used. The use of logic also means that it is not only the form of inferences that matters, but their content, too, even in the case of valid inferences. Therefore, from an argumentation theoretical point of view, the interpretation of modus tollens suggested in the first column of the table is, of course, fully justified.

${ }^{39}$ The pattern of refuting the antecedent is dynamic (in the sense of Polya, see section 3.2), whereas that of denying the antecedent is not. The reason is that in the case of fallacies the second premise is not dynamic, because according to the traditional view inferences are static. 


\section{On the effectivity of (1) and (2)}

\subsection{The problem}

After we have clarified the difference between fallacies and plausible inferences, the question arises whether (1) and (2) are made a fallacious or a plausible use of in the three theories we are examining. By definition, this question should be reduced to the problem as to the effectivity of (1) and (2) in the given theoretical contexts.

However, examining whole theories is a very complicated and lengthy matter, therefore the problem should be further specified. How can we test whether the use of (1) and (2) is effective or not? One-but certainly not the only - way is to argue as follows. Firstly, we will choose a well-known paradigm example of fallacies. Let this example be petitio principii, because it is known as a typically ineffective strategy which does not yield new insights and does not contribute to the solution of the problems raised. It is especially interesting that in the literature all three theories have been accused of committing the fallacy of petitio principii. Secondly, we will try to show that by the use of (1) and (2) this fallacy, which would occur otherwise, can be avoided. If we succeed in showing this, then we may conclude, thirdly, that (1) and (2) have been used effectively, because with their help an ineffective strategy of reasoning could be avoided and therefore the heuristic capacity of the theory has been restored. Accordingly, our next question is:

(P3) Can by the use of (1) and (2) in the context of the three theories the fallacy of petitio principii be avoided? ${ }^{40}$

If it can, then the theories we are examining may be - at least with respect to the use of (1) and (2), provisionally and partially-legitimized as scientific enterprises. If not, then one must conclude that they are false theories built on fallacious reasoning.

\footnotetext{
${ }^{40}$ By petitio principii we mean in accordance with our characterization of fallacies ineffective or even destructive circularity which does not result in any new knowledge and serves only as self-legitimization.
} 


\title{
4.2. Generative linguistics
}

As regards generative linguistics, according to one of Chomsky's initial hypotheses, language is governed by rules. However, since this hypothesis cannot be tested by direct empirical evidence, the risk of circularity is relatively great:

\begin{abstract}
"Imagine a debate between radical regularists, like Chomsky, and moderate ones who are convinced that there is no regularity in language over and above the obvious cases of agreement, comparison of adjectives, etc. The opposing parties would soon be involved in vicious circles. [...] In fact, the very acceptability of the data relevant to the question seems to depend on a prior decision concerning the degree of systematicity of language. Hence the assumption of regularity cannot be regarded as a generalization from hard facts. I would like to suggest that it may be understood, partly, in terms of Chomsky's views on human nature. He thinks that creativity presupposes rules. So if language use is creative, it has to take place within a system of rules. Thus it might be the rules governing our creative activities where the principle of regularity comes from." $\quad$ (Forrai 1987, 51; emphasis added)
\end{abstract}

This kind of circularity can be avoided by the use of (2). In particular, as we have shown in section $\mathbf{2 . 2}$, the principle which says that linguistic competence is governed by rules was inferred from the properties of human nature via (2). Therefore, the reasoning does not return to the same state, but to a qualitatively different informational state. Consequently, the reasoning is not viciously circular; rather, it is cyclic and rests on the retrospective revalidation of the partial basis.

Nevertheless, in other contexts the circularity arises again from different "prismatic" points of view. For example, it is instructive to observe that in certain contexts of argumentation Chomsky reverses the inferential relationship between human nature and linguistic competence. It is not only the case that he infers properties of the latter from properties of the former, but also vice versa:

\footnotetext{
"Given the role of language in human life and probably human evolution, and given its intimate relations to what I have been calling 'common-sense understanding', it would not be very surprising to discover that other systems within cognitive capacity have something of the character of the language faculty and its products. We should anticipate that these other cognitive systems too set limits on human intellectual achievement, by virtue of the very structure that makes it possible to acquire rich and comprehensive systems of belief and knowledge, insight and understanding. I have already discussed this matter briefly in connection with the 'science-forming capacity' (whatever it may be)."

(Chomsky 1976, 123)
} 
Moreover, on the same page he also claims that even visual perception could have been chosen as a point of departure:

"I would like to stress again that these conjectures should not seem in any way surprising to the natural scientist. Rather, they conform reasonably well to what is known about how the brain works in other domains, say, the construction of visual space and the objects in it. Furthermore, as a number of biologists have pointed out, something of the sort is to be expected on simple evolutionary grounds."

(Chomsky op.cit., 123f)

At a later point in the same work he reverses the direction of argumentation again: "If the approach to the study of cognitive capacity outlined earlier is a proper
one, then we can hope to develop a theory of human nature in its psycho-
logical aspects. [...] No one would seriously argue today, for example, that
our construction of perceptual space is guided by empiricist maxims. The
same, I think, is true of the language faculty, which relates more closely to
the essential nature of the human species."
(ibid., 125f)

Then he handles the study of linguistic competence and human cognition simultaneously:

\begin{abstract}
"Imagine a scientist, henceforth S, who is unencumbered by the ideological baggage that forms part of our intellectual tradition [...]. S might begin with the observation that people seem to act in systematic ways with respect to the objects around them and that they use and respond to expressions in organized ways. He might also conclude that humans, rather early in their lives, seem to arrive at steady states of development in these respects, states which provide a basis for human actions and responses. [...] S might now proceed to characterize these steady states, attributing to the organism two cognitive structures: (i) a system of beliefs and expectations about the nature and behavior of objects, and (ii) a system of language. Suppose he calls the first system 'common sense' and the second 'grammar'." (ibid., 139)
\end{abstract}

Although these quotations suggest that Chomsky's argumentation still appears to be circular, the point is that the premises and the conclusions of the inferences of types (1) and (2) correspond to different informational stages and are thus "at a different cognitive level" (Rescher 1976, 119). The credibility of Chomsky's argumentation is significantly enhanced by the fact that inferences from the whole to the part and from the part to the whole are not restricted to single properties, but rather, affect a coherent network of properties. Accordingly, besides certain single properties, linguistic competence, human nature and society are related by structural similarities - that is by relations between corresponding elements - as well. Consequently, whole-part and part-whole inferences are 
closely connected to a system of analogical inferences (see also the first quotation from Forrai in section 2.2). In a nutshell, linguistic competence, human nature and society are governed by regularities; these regularities presuppose the creative behaviour of people; creativity, however, can be manifested in behaviour characterized by regularities; the regularities are not arbitrary, but can operate only within man's biological constraints; it is, however, these constraints that enable human beings to act freely and creatively. See Figure 6 as the extension of Figure 1 with respect to these relations.

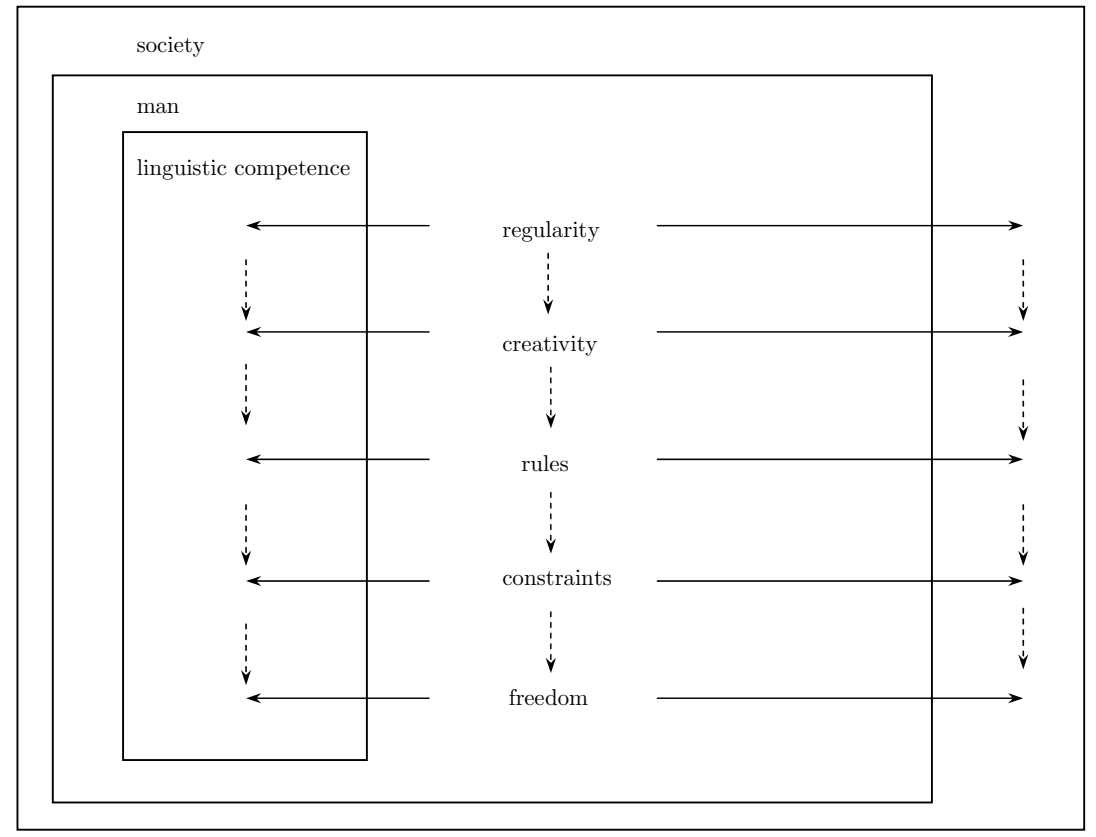

Fig. 6

These structural relationships facilitate the application of Chomsky's model of linguistic competence to other areas of cognition, and in doing so, he tests his hypotheses on the basis of continuously modified amounts of information. As long as his approach can be applied to other fields of human cognitive behaviour as well, all these assumptions clearly enhance each other's credibility. This means that as a result of drawing inferences along the lines of (1) and (2), a strong analogy between man, linguistic competence and society is established. ${ }^{41}$

${ }^{41}$ As Gentner and Markman emphasize, it is this systematicity that is responsible for the effectivity of analogical reasoning: 
Consequently, our considerations seem to support the assumption that Chomsky's reasoning is cyclic and prismatic (see section 3.4) rather than circular (Figure 7).

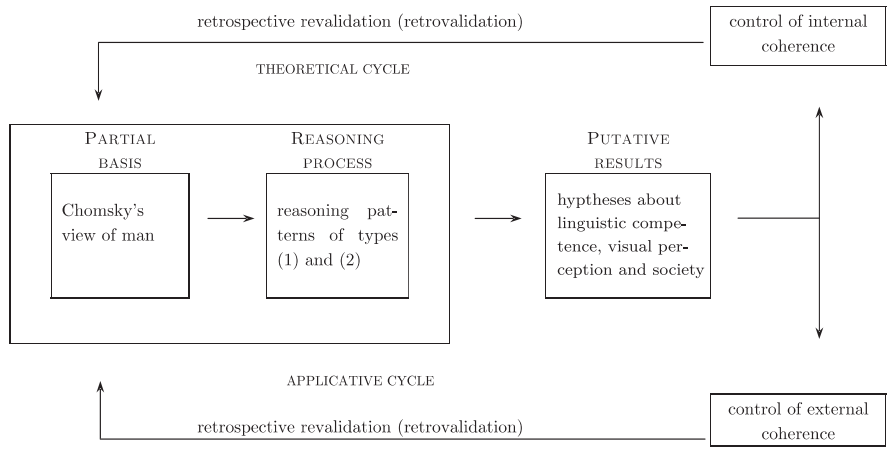

Fig. 7

This cycle can be supplemented by further pieces of information, for example, the basic assumptions of a certain version of generative grammar:

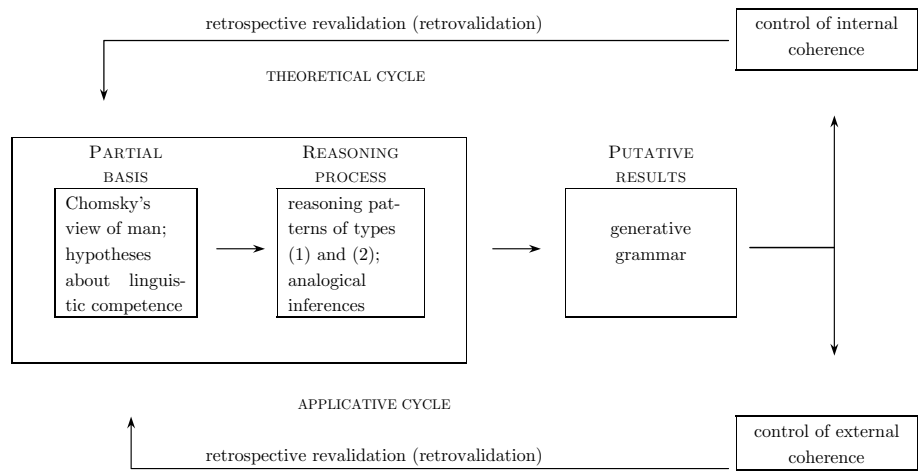

Fig. 8

\begin{abstract}
"The defining characteristic of analogy is that it involves an alignment of relational structure. [...] Analogies tend to match connected systems of relations [...]. A matching set of relations interconnected by higher order constraining relations makes a better analogical match than an equal number of matching relations that are unconnected to each other. The systematicity principle captures a tacit preference for coherence and causal predictive power in analogical processing."
\end{abstract}

(Gentner-Markman 1997, 47)

Thus, the relationship between whole-part and part-whole inferences on the one hand and such a systematic use of analogies on the other hand, clearly increases the effectivity of the former. 
Thus, (1) and (2) play an important heuristic role, because the basic background assumptions of the theory are obtained with their help.

So as to evaluate these findings, it is worth remarking that, however different the particular versions of Chomsky's generative grammar are, they remain within the boundaries of the inferences reconstructed in (3)-(9). For example, both the Standard Theory and GB Theory make substantial use of (3), irrespective of the fact that the content of the particular inferences is different. This means that although these versions focus on partly differing ideas - for example the Standard Theory focuses on rules, while GB theory centres on freedom within constraints and in the case of minimalism it is constraints that are emphasized-, in this respect, too, (1) and (2) play an indispensable role in Chomsky's theory. The reason they do so is that the frequent use of inferences which are manifestations of the patterns (1) and (2) belong to the philosophical basis of Chomsky's work. One might object that this philosophical basis is not constitutive of Chomsky's linguistic theory that focuses on the technical innovations widely applied by linguists. However, this objection is clearly unmotivated. Unfortunately, we cannot go into a detailed proof of the latter claim, therefore, let us substitute such a proof by the following quotation which nicely summarizes the main issue:

\begin{abstract}
"[...] many linguists (including many practicing generative linguists) seem not to take much interest in Noam Chomsky's general ('philosophical') writings on the nature of language. [...] Among such linguists, there appears to be a sense that Chomsky's more general thinking about the nature of human language (as opposed to his more specific work, for example, within the current Chomskyan model known as the Minimalist programme) represents merely 'the philosophical side of (Chomskyan) linguistics', an area that is viewed by many linguists as being, in some sense, an optional extra, distinct from, and not having any obvious direct bearing on, the business of getting on with doing linguistic analyses ('linguistics proper' as opposed to philosophy). This outlook is unfortunate, since foundational ideas are surely what any significant linguistic theory is derived from. It is certainly the more general issues which drive Chomsky's thinking, and from which the Minimalist programme and all its predecessors are derived."
\end{abstract}

(Carr 2003, 615; emphasis added)

Thus our argument is simple: if the use of (1) and (2) is effective for the philosophical foundations of Chomsky's theory and these foundations are effective for all the versions of this theory, then (1) an (2) are effective not only for Chomsky's philosophy, but also for his "linguistics proper". 


\title{
4.3. The two-level approach
}

According to Müller (1991) the fallacy of petitio principii characterizes modular approaches to cognition generally:

\begin{abstract}
"Ein logischer Fehlschluß, der sich immer wieder in modularistischen Theorien der Kognitiven Wissenschaften finden läßt, ist die Interpretation forschungsstrategisch motivierter Abgrenzungen als realistische Aussagen über die Organisation von Geist und Gehirn. Daß wir die Welt oder unseren eigenen Geist vielleicht nur durch einen modularistischen 'Theoriefilter' erkennen können, bedeutet nicht, daß Welt und Geist modular sind."
\end{abstract}

(Müller op.cit., 407; emphasis added)

This applies to the two-level approach, too - all the more so, because its main empirical hypothesis says that "all human cognitive behaviour is organized in a modular fashion".

In the two-level approach very much depends on the assumption that there is a set of modules. However, proving the existence of relatively autonomous systems and subsystems is one of the most difficult tasks of modularism, because there is a substantial lack of empirical evidence (whatever "empirical evidence" may mean). Therefore, the two-level approach runs the risk of circularity as well. In particular, its proponents accept the empirical hypothesis that knowledge of language is based on the interaction of relatively autonomous systems, because, for methodological reasons, the object of investigation can be grasped only by systematic simplifications, namely, its subdivision into separate (sub)systems. At the same time, however, they accept the methodological principle that the object of investigation has to be subdivided into relatively autonomous systems, because they have accepted the empirical hypothesis, according to which knowledge of language consists of subsystems. ${ }^{42}$ This circular reasoning seems to be clearly formulated for example in the following passage from one of the seminal works by Bierwisch and Lang:

"Singling out autonomous subsystems of mental organization and specifying their content is based on the assumption that the structure and the functioning of cognitive systems do indeed have such a modular structure. Autonomous subsystems and structural levels of the theory, from this factual point of view, correspond to autonomous subsystems in the actual structure of mental states and processes. This actual structure, however, cannot be discovered directly but only in the form of explanatory theories. From this

${ }^{42}$ See Müller (ibid.) and Kertész (2004a) for a detailed discussion of the modularistic circle. 
theoretical point of view, identifying subsystems and explaining their autonomy, as well as finding out the nature of their interaction, becomes an aspect of adequate theory formation. Autonomous components of the theory are then justified (a) by the independence of the basic concepts, (b) by the internal structure of the theoretical components which the basic concepts enter and (c) by the possibility of formulating regularities in the framework of (a) and (b) which explain the facts on the appropriate level of abstraction."

(Bierwisch-Lang 1989, 495; emphasis added)

However, research within the two-level approach can be seen as a series of cyclically proceeding plausible inferences, rather than being circular. Namely in section $\mathbf{2 . 3}$ we have shown that the two-level approach uses (1) and (2) as constitutive tools of theory-formation. Therefore, if one interprets the last quotation on the basis of the framework we introduced in section 3, then it follows immediately that (1) and (2) contribute to the resolution of the circularity and to the generation of a cyclic and prismatic reasoning mechanism. Figure 9 is intended to illustrate the cyclicity of reasoning within the two-level approach.

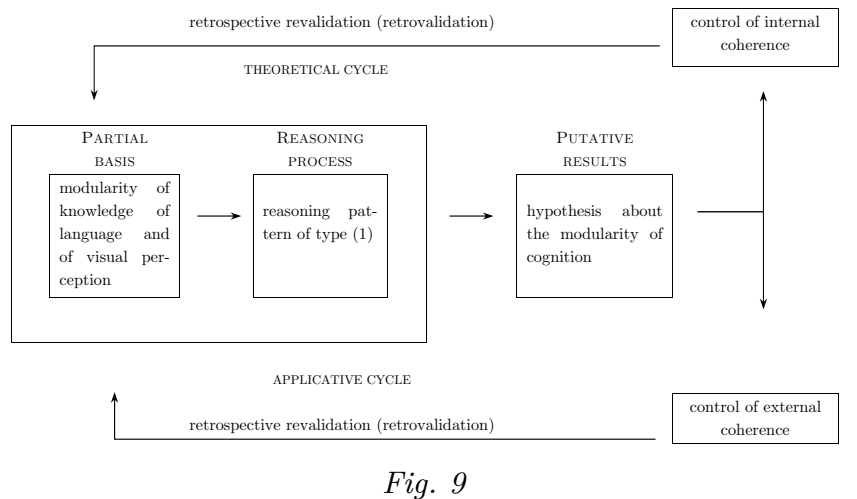

Although at every point of the argumentation proponents of the two-level approach try to identify the major premises and to argue clearly on their basis, evidently we must not exclude the possibility that there is indeed an "invisible part" of the basis (see section 3.2). This invisible part involves those assumptions of the two-level approach which one does not make use of in the argumentation explicitly and whose indirect consequences one cannot realize - for example the "empirical evidence" (in whatever sense) supporting the autonomy of what the two-level approach calls "semantic form". We may conclude that it is the particular argumentative context within the two-level approach that decides whether the applications of (1) 
and (2) are plausible or fallacious, because (a) the modules whose existence the argumentation hinges on are heuristically motivated theoretical constructs, and (b) apart from the "visible basis" of the argumentation there is an "invisible basis" (in the sense of Polya 1948, 223f, quoted in section 3.2), whose implications may be different from those of the visible one-for instance, if the "empirical evidence" turned out to refute the autonomy of semantic form and that of the conceptual module.

Therefore, the use of (1) is, due to the cyclic nature of the argument, clearly effective. That is, the application of (1) is to be interpreted as plausible rather than fallacious. This situation can be retained as long as the starting hypotheses - that is, the partial basis - are considered to be plausible. However, as soon as serious arguments arise against the modularity of the knowledge of language to which the theory cannot react convincingly, the plausibility of (1) has to be subjected to revision.

Moreover, as Figure 10 suggests, in later cycles the two level approach uses the assumption of modularity as a premise and thus applies (2), too (see also section $\mathbf{3 . 3}$ ).

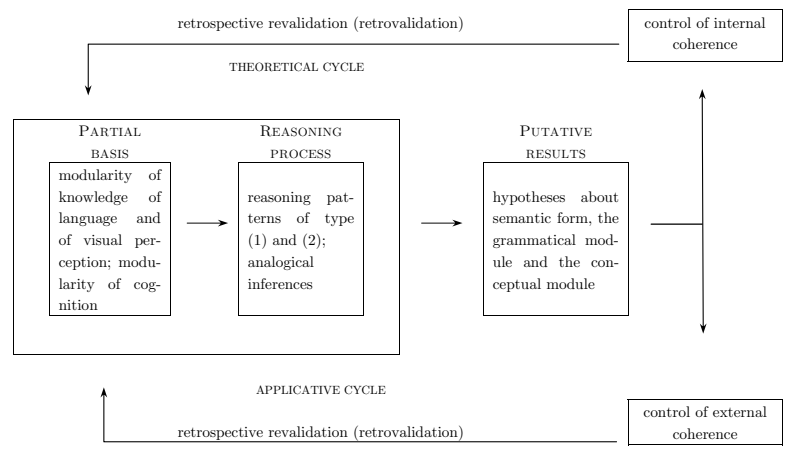

Fig. 10

\subsection{The cognitive theory of metaphor}

Critics of Lakoff and Johnson's approach have recently argued that the authors commit the fallacy of petitio principii. For example, Haser (2005, $145 \mathrm{ff})$ enumerates and analyzes such cases in great detail; see also Murphy $(1996,183)$. To mention another source, McGlone accuses Lakoff and Johnson of the following fundamental error which he thinks clearly undermines their whole approach: 
"[...] Lakoff's claim that metaphors transcend their linguistic manifestations to influence conceptual structure rests solely on these manifestations. How do we know that people think of theories in terms of buildings? Because people often talk about theories using building-related expressions. Why do people often talk about theories using building-related expressions? Because people think about theories in terms of buildings. Clearly, the conceptual metaphor view must go beyond circular reasoning of this sort and seek evidence that is independent of the linguistic evidence."

(McGlone 2001, 95; emphasis added)

That is, Lakoff and Johnson infer the existence of metaphorical concepts from the use of metaphorical expressions, and they infer the use of metaphorical expressions from the existence of metaphorical concepts. It is important to emphasize right at the outset that Lakoff and Johnson's reasoning is much more difficult to reconstruct than Chomsky's and Bierwisch and Lang's. Namely, the former argue simultaneously into two opposing directions (cf. (25) and (39)), while they do not differentiate between these two lines of argumentation systematically. ${ }^{43}$

Let us begin with the first direction. From a methodological point of view, metaphorical expressions are primary, because the following is assumed: ${ }^{44}$

(24) The cognitive theory of metaphor infers properties of metaphorical concepts from properties of metaphorical expressions.

The problem of circularity is closely related to (24), because it concerns the methodological question of how to account for the inferential connection between linguistic expressions and concepts. Therefore, before turning to the role (1) and (2) play in the resolution of circularity, we have to discuss the chain of inferences which belong to the methodological line of reasoning summarized in (24). ${ }^{45}$ As we will see, (27)-(31)

${ }^{43}$ Therefore, the whole of their reasoning is present simultaneously at every stage and it is hard to reconstruct it as a linear sequence of inferences. What the conclusion and what the premise is depends basically on the particular point at which one interrupts the reasoning and begins with the reconstruction.

44 "Since metaphorical expressions in our language are tied to metaphorical concepts in a systematic way, we can use metaphorical linguistic expressions to study the nature of metaphorical concepts and to gain an understanding of the metaphorical structure of our activities." (Lakoff-Johnson 1980, 7; emphasis added)

${ }^{45}$ Please note that the inferences discussed in the present section are plausible and not deductively valid. That is, their conclusion is only credible to a certain extent and not true with certainty. For the precise structure of shaded modus 
below increase the plausibility of (24), and with the help of (1) and (2) further conclusions can be drawn.

Lakoff and Johnson seem to accept the principle that "one can move freely and gradually from facts about language to facts about human cognition and further on to facts about human life generally [...]" (Harder 1999, 196). However, the structure of such a "move" is anything but clear:

"The trouble with Lakoff/Johnson's position is this: All that Lakoff/Johnson's data show is that we employ certain expressions (rather than concepts) that can-but need not - be associated with the domain of WAR. Demonstrating the presence of metaphorical concepts is impossible on the basis of purely linguistic evidence (cf. Murphy 1996). How is the jump from language to thought justified? Lakoff/Johnson (1980: 5) do not tackle this question, merely repeating their principal claim again."

(Haser 2005, 147; italics as in the original, bold emphasis added)

Our model of plausible reasoning outlined in section 3 suggests the following reconstruction of the inference Harder and Haser refer to:

(25) Premises:

(a) Linguistic expressions associated with arguments are metaphorical.

(b) (Between linguistic expressions and concepts there is such a relationship that from properties of linguistic expressions one may infer properties of concepts.)

Conclusion:

(c) The concept ARGUMENT is metaphorically structured.

Our model explains Haser's $(2005,147)$ criticism by interpreting $(25 \mathrm{~b})$ as an "invisible" premise (in the sense of Polya, see section 3.2) whose particular content is not known. ${ }^{46}$ This is especially interesting, because, as we know, plausible reasoning proceeds, among other things, in such a way that the partial basis contains alternative assumptions between which one can choose only by examining "the credibility", "the weight", "the strength" of each of them in the light of the particular informational state. In the present case, the alternatives one of which should specify (25b) may be for example the following.

tollens and shaded modus ponens see Tables 1 and 2 in section 3.5. The reason for reconstructing the following inferences in a simplified form-i.e., for omitting the plausibility-indicators ("possible", "less credible", "more credible", "certain", etc.) - is that otherwise our analyses would be too complex and difficult to capture for the reader.

${ }^{46}$ Invisible premises are marked by "〈" and "〉". 
(26) Alternative premises in the partial basis:

(a) Meanings and concepts are the same and "linguistic expression" is a shorthand for "the meaning of a linguistic expression".

(b) Meanings are part of the conceptual system and "linguistic expression" is shorthand for "the meaning of a linguistic expression".

(c) Meanings and concepts are analogous and "linguistic expression" is shorthand for "the meaning of a linguistic expression".

(d) Meanings and concepts are isomorphic and "linguistic expression" is shorthand for "the meaning of a linguistic expression".

(e) Linguistic expressions are indices of concepts.

(f) etc.

Nevertheless, one may argue that both Haser's criticism and our reconstruction of Lakoff and Johnson's reasoning in (25) and (26) are incorrect, because in the cognitive theory of metaphor the inferential connection between the metaphoricity of linguistic expressions and that of concepts is defined clearly:

"If metaphors were merely linguistic expressions, we would expect different linguistic expressions to be different metaphors. Thus, 'We've hit a dead-end street' would constitute one metaphor. 'We can't turn back now' would constitute another, entirely different metaphor. 'Their marriage is on the rocks' would involve still a different metaphor. And so on for dozens of examples. Yet we don't seem to have dozens of different metaphors here. We have one metaphor, in which love is conceptualized as a journey." (Lakoff 1993, 209)

The structure of this argument is that of shaded modus tollens (cf. 3.5) which is a typical pattern of plausible inference:

(27) Premises:

(a) If metaphors were merely linguistic expressions, then different linguistic expressions would be different metaphors.

(b) It is not the case that different linguistic expressions are different metaphors.

Conclusion:

(c) Metaphors are not merely linguistic expressions.

Furthermore, the idea of systematicity also plays an important role:

"The LOVE IS A JOURNEY metaphor and Reddy's Conduit Metaphor were the two examples that first convinced me that metaphor was not a figure of speech, but a mode of thought, defined by a systematic mapping from a 
source to a target domain. What convinced me were the three characteristics of metaphor that I have just discussed:

1. The systematicity in the linguistic correspondences.

2. The use of metaphor to govern reasoning and behavior based on that reasoning.

3. The possibility for understanding novel extensions in terms of the conventional correspondences." $\quad$ (Lakoff 1993, 210; emphasis added)

This argumentation can be reconstructed the following way: ${ }^{47}$

(28) Premises:

(a) If metaphors in connection with love were merely linguistic expressions, then there would be no systematicity among them.

(b) There is systematicity among linguistic expressions in connection with love.

Conclusion:

(c) Metaphors in connection with love are not merely linguistic expressions.

Lakoff (1993) uses (28c) as a premise supplemented by an analogy between metaphorical expressions associated with love: ${ }^{48}$

(29) Premises:

(a) If metaphors in connection with love are not merely linguistic expressions and we systematically speak about love as if it were a journey when metaphorical expressions associated with love are used, then there is a systematic mapping from the conceptual domain JOURNEY to the conceptual domain LOVE when we speak about love.

(b) Metaphors in connection with love are not merely linguistic expressions and we systematically speak about love as if it were a journey when metaphorical expressions associated with love are used.

Conclusion:

(c) There is a systematic mapping from the conceptual domain JOURNEY to the conceptual domain LOVE when we speak about love.

Similarly to (29), Lakoff (ibid.) obtains (30) as well: ${ }^{49}$

${ }^{47}$ The structure of this argument is that of shaded modus tollens, too.

48 The structure of this argument is that of shaded modus ponens.

${ }^{49}$ The structure of this argument is that of shaded modus ponens, too. 
(30) Premises:

(a) If metaphors in connection with love are not merely linguistic expressions and we systematically use patterns of inference about journeys to reason about love when metaphorical expressions associated with love are used, then there is a systematic mapping from one conceptual domain to the other when we reason about love.

(b) Metaphors in connection with love are not merely linguistic expressions and we systematically use patterns of inference about journeys to reason about love when metaphorical expressions associated with love are used.

Conclusion:

(c) There is a systematic mapping from one conceptual domain to the other when we reason about love.

The next link in the chain is an analogical inference which contains "invisible" premises as well:

(31) Premises:

(a) There is a systematic mapping from the conceptual domain JOURNEY to the conceptual domain LOVE when we speak about love.

(b) There is a systematic mapping from one conceptual domain to the other when we reason about love.

(c) The connection between the two conceptual domains is in both cases always metaphorical, i.e., a unidirectional mapping between the source domain and the target domain. ${ }^{50}$

(d) 〈The conceptual domain LOVE as well as the conceptual domain JOURNEY are the same when we talk and when we reason about love.)

(e) (There is no difference between the principles governing how we speak about love and the principles governing how we reason about love.

Conclusion:

(f) There is only one set of principles governing speaking and reasoning about love, i.e., the concept LOVE is metaphorically structured. ${ }^{51}$

50 " [...] the metaphor can be understood as a mapping (in the mathematical sense) from a source domain (in this case, journeys) to a target domain (in this case, love)." (Lakoff op.cit., 206)

51 "As a linguist and a cognitive scientist, I ask two commonplace questions: Is there a general principle governing how these linguistic expressions about journeys are used to characterize love?

Is there a general principle governing how our patterns of inference about journeys are used to reason about love when expressions such as these are used?

The answer to both is yes. Indeed, there is a single general principle that answers 
Just as in the case of (25), here it is also the very information specifying the connection between the metaphorical structure of linguistic expressions and that of concepts that is missing from the "visible" part of the partial basis.

After having explicated the inferential chain leading from metaphorical expressions to metaphorical concepts, let us turn to the role (1) and (2) play in Lakoff and Johnson's reasoning. Chapters 1 and 2 of LakoffJohnson (1980) witness that (1) and (2) undoubtedly assume a key position in the argumentative strategies the authors apply. For example this means that, after having analyzed a number of linguistic expressions and found that they are metaphorical, they conclude that language is metaphorical (see Figure 11):

(32) Premises:

(a) The concept of LOVE is part of the conceptual system underlying language. ${ }^{52}$

(b) The concept of LOVE is metaphorically structured. ${ }^{53}$

Conclusion:

(c) The conceptual system underlying language is metaphorically structured.

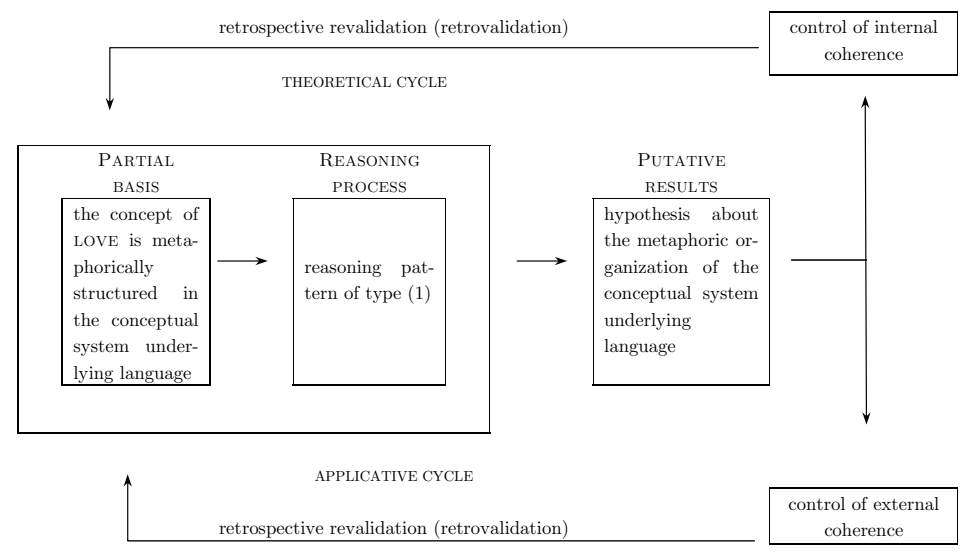

Fig. 11

both questions. But it is a general principle that is neither part of the grammar of English, nor the English lexicon. Rather, it is part of the conceptual system underlying English: It is a principle for understanding the domain of love in terms of the domain of journeys." (Idem.; emphasis added)

${ }^{52} \mathrm{Cf}$. "The conceptual system underlying a language contains thousands of conceptual metaphors - conventional mappings from one domain to another, such as the Event Structure Metaphor." (Ibid., 239; emphasis added)

${ }^{53}$ Cf. (31a) and (c).

Acta Linguistica Hungarica 52, 2005 
In analogy to (32), from (30c) they obtain (33) via (1) (see Figure 12):

(33) Premises:

(a) The concept of LOVE is part of the conceptual system underlying reasoning.

(b) The concept of LOVE is metaphorically structured. ${ }^{54}$

Conclusion:

(c) The conceptual system underlying reasoning is metaphorically structured.

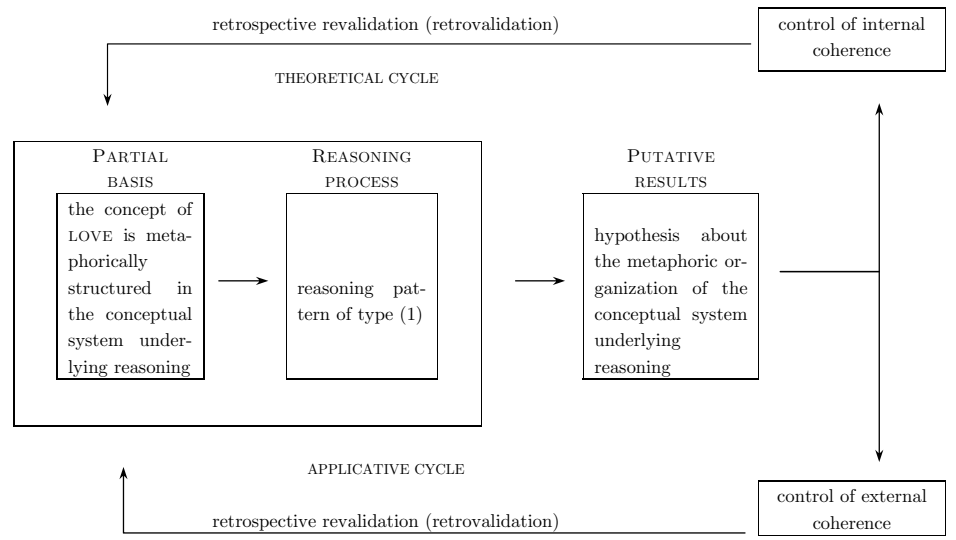

Fig. 12

Via (1) from (31d), (34) is obtained:

(34) Premises:

(a) The conceptual domain LOVE as well as the conceptual domain JOURNEY are the same when we talk and when we reason about love.

(b) The concepts LOVE and JOURNEY are part of the conceptual system underlying language and of the conceptual system underlying reasoning.

Conclusion:

(c) Thinking and language rest on the same conceptual system, i.e., there is only one conceptual system underlying language and reasoning. ${ }^{55}$

Similarly, (31e) can be extended to the whole of the conceptual system as well (Figure 13):

${ }^{54}$ Cf. (31b) and (c).

${ }^{55} \mathrm{Cf}$. "[...] communication is based on the same conceptual system that we use in thinking and acting." (Lakoff - Johnson 1980, 4; emphasis added)

Acta Linguistica Hungarica 52, 2005 
(35) Premises:

(a) The concept of LOVE is part of the conceptual system.

(b) The concept LOVE is metaphorically structured.

Conclusion:

(c) The conceptual system is metaphorically structured.

(35c) is one of the central hypotheses of Lakoff and Johnson's theory. ${ }^{56}$

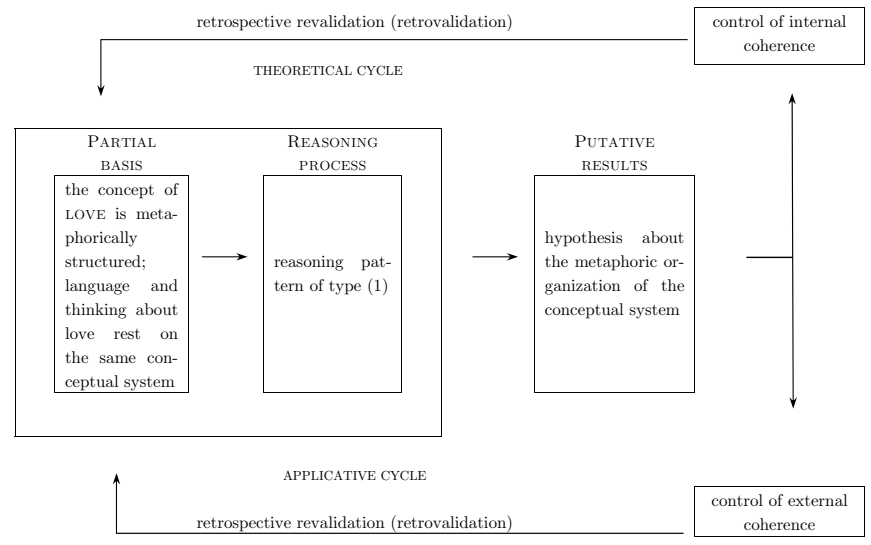

Fig. 13

However, Lakoff and Johnson also postulate the inverse relationship between metaphorical expressions and metaphorical concepts. Whereas metaphorical expressions are, as we have seen in (24), methodologically primary with respect to metaphorical concepts, from an ontological point of view they are secondary, because the following is assumed:

(36) Metaphorical expressions are the linguistic manifestations of metaphorical concepts. $^{57}$

56 "[...] the human conceptual system is metaphorically structured [...]." (Ibid., 6)

57 "Metaphors as linguistic expressions are possible precisely because there are metaphors in a person's conceptual system." (Idem.)

"Metaphor is fundamentally conceptual, not linguistic, in nature. Metaphorical language is a surface manifestation of conceptual metaphor." (Lakoff 1993, 244)

For example, the conceptual metaphor LOVE IS A JOURNEY is manifested in the metaphorical expressions this relationship is foundering, we are going nowhere, this relationship is a dead-end street, we are at a crossroads, etc. 
Accordingly, the authors also argue in the opposite direction than (24) suggests, because they explain certain characteristics of metaphorical expressions on the basis of characteristics of metaphorical concepts. Therefore, for each inference of the methodological cycles there can be an inverse inference in one of the ontological cycles. For example, by the use of (2), the following inferences are carried out:

(37) Premises:

(a) Abstract concepts are part of our conceptual system.

(b) Our conceptual system is metaphorically structured.

Conclusion:

(c) Abstract concepts are metaphorically structured.

(38) Premises:

(a) Our conceptual system is metaphorically structured.

(b) The concept ARGUMENT is part of our conceptual system.

Conclusion:

(c) The concept ARGUMENT is metaphorically structured.

(39) Premises:

(a) Our conceptual system is metaphorically structured.

(b) (Between linguistic expressions and concepts there is such a relationship that from properties of concepts one may infer properties of linguistic expressions.)

Conclusion:

(c) Linguistic expressions are metaphorically structured.

In the case of (39b) obviously the same problem of the invisible part of the partial basis arises as with (25), therefore the alternatives in (26) apply here, too. Thus we obtain the situation represented in Figure 14.

At this point we may risk the following conclusions:

Firstly, although the "jump" (Haser 2005) from linguistic expressions to concepts seems to be unmotivated and circular at first sight, this circularity can be avoided. The reason is that by inferring the existence of metaphorical concepts from the use of metaphorical expressions and the use of metaphorical expressions from the existence of metaphorical concepts, "one indeed returns to 'the same point' but does so at a different cognitive level" (Rescher 1987, 119). In particular, the difference 


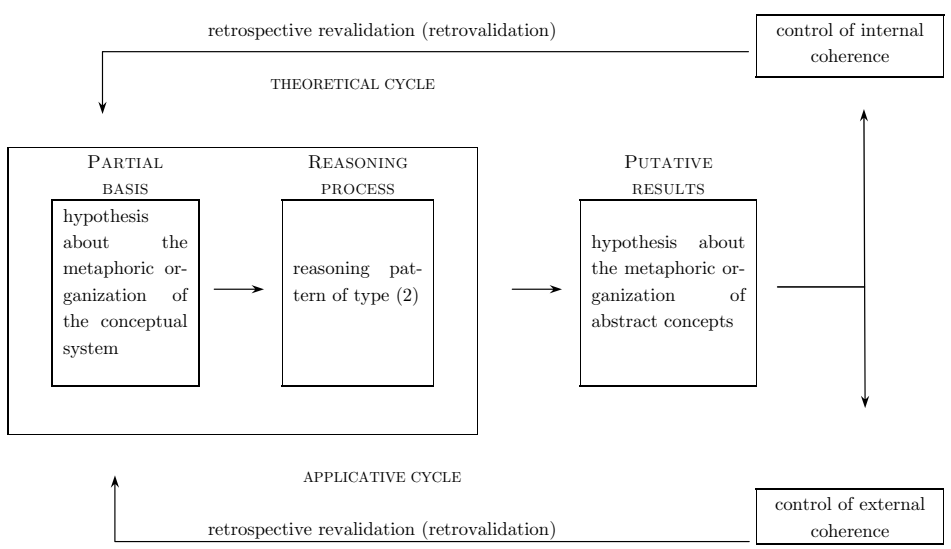

Fig. 14

between the two "cognitive levels" is that whereas one is methodological, the other is ontological. This finding resolves the circularity: the "jump" is nothing but a process of cyclic and prismatic revalidation that makes extensive use of (1) and (2). Therefore, from this point of view, the latter are effective, rather than ineffective: the gap between the metaphorical structure of linguistic expressions and the metaphorical structure of concepts can be filled only by the continuous retrospective revision of the basis, looking for the missing information in the hope that its invisible parts will eventually become visible.

Secondly, in Lakoff and Johnson's approach (1) and (2) contribute to turning the potential circularity of the argumentation into cyclic and prismatic reasoning. ${ }^{58}$ Therefore, in this respect they are to be evaluated as effective.

Thirdly, what Lakoff and Johnson failed to do is the plausibility analysis of the alternatives which should be expected to specify the "invisible premises" in (25), (31) and (39).

Fourthly, in a series of cases even the plausibility of the "visible" premises can be seriously questioned. For example, several of the claims which Lakoff and Johnson use as premises clearly overgeneralize (see e.g., (28b), (30b)).

${ }^{58}$ However, this must not mean that other parts of Lakoff and Johnson's theory are not harmfully circular. For example, among the many passages whose circularity Haser (2005) reveals there may be several which are clear cases not of cyclical reasoning, but of petitio principii. See also Kertész-Rákosi (2005a). 
In sum, although we tried to show the effective use of (1) and (2) in Lakoff and Johnson's reasoning, the question has to be left open whether the particular handling of the partial basis in a series of other inferences remains within the realm of plausible reasoning or transgresses the boundary which divides the latter from fallacies.

\subsection{Summary}

In section 4 we tried to show that in the case of all three theories the use of the patterns (1) and (2) plays an important heuristic role. That is, we have obtained the following solution to (P3):

(H3) (a) By the use of (1) and (2) the fallacy of petitio principii can be avoided in the given contexts in the three theories.

(b) Therefore, the use of (1) and (2) is effective.

(c) Therefore, they work as plausible rather than as fallacious inferences.

\section{The solution to (D)}

In sections 2-4 we supported the auxiliary hypotheses (H1)-(H3). These, in turn, yield immediately $(\mathrm{H})$ which is our solution to $(\mathrm{P})$. $(\mathrm{H})$ suggests the following further considerations:

(i) On the one hand, our analyses imply that with respect to the structure of inferences we analyzed, a holistic cognitive semantic theory which explicitly rejects both generativism and modular cognitive linguistics is in reality not as different from the latter as is commonly assumed, because it uses the same patterns of inference (1) and (2).

(ii) On the other hand, generative linguistics and modular cognitive linguistic theories compatible with the latter behave in a way radically different from the way they claim to operate in, because the inferences they use to support their central hypotheses are far from the standards of the "received view" of the analytical philosophy of science. In particular, in opposition to (RVb), it is plausible rather than demonstrative inferences that these theories rest on.

(iii) We have seen that the standards of rationality which these theories do make use of are essentially different from what (RVa) requires.

(iv) We have also seen that $(\mathrm{RVc})$ is untenable in the case of the investigated linguistic theories. It is not possible to distinguish sharply 
between "the context of discovery" and "the context of justification", because every stage of theory formation is substantially determined by the use of plausible reasoning.

(v) Moreover, our considerations also witness that the heuristic strategies applied in generative, modular cognitive and holistic cognitive linguistics may make use of patterns of inference which are borderline cases between plausible reasoning and fallacious inferences. One cannot exclude at the outset that (1) and/or (2) seem to be plausible within one particular cycle of reasoning, while they turn out to be fallacious in the context of another cycle, or vice versa. This is a serious difficulty, because plausible and fallacious inferences differ substantially. In spite of their uncertainty, plausible inferences are fruitful, progressive and effective tools of scientific problem solving, while fallacies are destructive.

(vi) We chose very different examples to illustrate the wide applicability of (1) and (2). Thus the problems which the three theories try to solve with the help of (1) and/or (2) were very different in our analyses. In our example, Chomsky uses these patterns to establish the philosophical basis of his linguistic theory. Bierwisch and Lang infer their central empirical hypotheses via (1) and (2). Lakoff and Johnson make use of (1) and (2) in a large number of different theoretical contexts.

In the light of these findings there is no doubt that $(\mathrm{H})$ motivates the complete and comprehensive revaluation of central aspects of theory formation in linguistics in general and cognitive linguistics in particular. However, the strength of this insight is substantially weakened by the fact that we ourselves, too, argued by starting from a partial basis with invisible premises, and drew plausible inferences from this incomplete and uncertain informational base. Our own argumentation itself suggests that in applying the technique of plausible reasoning one is well-advised to remember Walton's warning:

\footnotetext{
"It is vitally important for the user of plausible argument to be open-minded, steering a mid-path between respecting the facts of a case and asking critical questions. The two main faults are the extremes of being dogmatic and leaping too quickly or too firmly to a questionable conclusion. Being dogmatic is a failure to be open to further dialogue. Leaping too quickly or too firmly may be a failure to seek more evidence, or even a closure to new evidence."

(Walton 2001, 164f)
} 


\section{References}

Bierwisch, Manfred 1987. Linguistik als kognitive Wissenschaft. Erläuterungen zu einem Forschungsprogramm. In: Zeitschrift für Germanistik 8:645-67.

Bierwisch, Manfred - Ewald Lang (eds) 1989. Dimensional adjectives: Grammatical structure and conceptual interpretation. Springer, Berlin \& Heidelberg \& New York.

Bremer, Manuel 2005. An introduction to paraconsistent logics. Lang, Frankfurt am Main.

Carr, Philip 2003. Innateness, internalism and input: Chomskyan rationalism and its problems. In: Language Sciences $25: 615-35$.

Chesñevar, Carlos Iván-Ana Gabriela Maguitman-Ronald Prescott Loui 2000. Logical models of argument. In: ACM Computing Surveys (CSUR) 32:337-83.

Chomsky, Noam 1976. Reflections on language. Fontana \& Collins, Glasgow.

Chomsky, Noam 1979. Language and responsibility. Pantheon, New York.

Chomsky, Noam 2000. New horizons in the study of language and mind. Cambridge University Press, Cambridge.

Copi, Irving M. - Keith Burgess-Jackson 1996. Informal logic. Prentice Hall, New Jersey.

Eemeren, Frans H. van - Rob Grootendorst 1994. The fallacies of composition and division. Ms. (http://www.illc.uva.nl/j50/contribs/eemeren/)

Eemeren, Frans H. van - Rob Grootendorst 2004. A systematic theory of argumentation. The pragma-dialectical approach. Cambridge University Press, Cambridge.

Eemeren, Frans H. van - Rob Grootendorst - Francisca Snoeck Henkemans 1996. Fundamentals of argumentation theory. Lawrence Erlbaum, Mahwah NJ.

Fanselow, Gisbert-Sascha W. Felix 1987. Sprachtheorie. (Vols. 1-2). Francke, Tübingen.

Fodor, Jerry A. 1983. The modularity of mind. An essay on faculty psychology. MIT Press, Cambridge MA.

Forrai, Gábor 1987. The role of a metaphor in the birth of generative grammar. In: Doxa $9: 49-55$.

Gentner, Deidre-Arthur B. Markman 1997. Structure mapping in analogy and similarity. In: American Psychologist 52:45-56.

Hamblin, Charles L. 1970. Fallacies. Methuen, London.

Hansen, Hans V.- Robert C. Pinto (eds) 1995. Fallacies. Classical and contemporary readings. Pennsylvania State Univiversity Press, University Park PA.

Harder, Peter 1999. Partial autonomy, ontology, and methodology in cognitive linguistics. In: Theodorus A. Janssen-Gisela Redeker (eds): Cognitive lingusitics: Foundations, scope, and methodology, 195-222. Mouton de Gruyter, Berlin \& New York.

Haser, Verena 2005. Metaphor, metonymy, and experiantialist philosophy. Challenging cognitive semantics. Mouton de Gruyter, Berlin \& New York.

Johnson, Ralph H. 1995. The blaze of her splendors: Suggestions about revitalizing fallacy theory. In: Hansen-Pinto (1995, 107-19).

Acta Linguistica Hungarica 52, 2005 
Kertész, András 2004a. Cognitive semantics and scientific knowledge: Case studies in the cognitive science of science. Benjamins, Amsterdam \& Philadelphia.

Kertész, András 2004b. Philosophie der Linguistik: Studien zur naturalisierten Wissenschaftstheorie. Narr, Tübingen.

Kertész, András-Csilla Rákosi 2005a. Circular vs. cyclic reasoning in cognitive theories of metaphor. In preparation.

Kertész, András - Csilla Rákosi 2005b. Inconsistency and plausible inferences in an analysis of German affricates. A case study in the philosophy of linguistics. In: Language Sciences. Forthcoming.

Kertész, András - Csilla Rákosi 2005c. Remarks on the cognitive base of pragmatic theories. In: Acta Linguistica Hungarica 52:5-40.

Kienpointner, Manfred 1992. Alltagslogik. Struktur und Funktion von Argumentationsmustern. Frommann-Holzboog, Stuttgart-Bad Canstatt.

Lakoff, George 1993. The contemporary theory of metaphor. In: Andrew Ortony (ed.): Metaphor and thought, 202-52. Cambridge University Press, Cambridge.

Lakoff, George-Mark Johnson 1980. Metaphors we live by. The University of Chicago Press, Chicago.

Lakoff, George-Mark Johnson 1999. Philosophy in the flesh. The embodied mind and its challenge to western thought. Basic Books, New York.

Lang, Ewald-Kai-Uwe Carstensen-Geoffrey Simmons 1991. Modelling spatial knowledge on a linguistic basis: Theory - prototype - integration. Springer, Berlin \& Heidelberg \& New York.

McGlone, Matthew S. 2001. Concepts as metaphors. In: Sam Glucksberg (ed.): Understanding figurative language: From metaphors to idioms, 90-107. Oxford University Press, Oxford.

Meheus, Joke (ed.) 2002. Inconsistency in science. Kluwer, Dordrecht.

Mittelstraß, Jürgen 2004. Vorwort. In: Jürgen Mittelstraß (ed.): Enzyklopädie Philosophie und Wissenschaftstheorie. Vol. 1, 5-10. Metzler, Stuttgart.

Murphy, Gregory L. 1996. On metaphoric representation. In: Cognition 60 : 173-204.

Müller, Ralph-Axel 1991. Der (un)teilbare Geist. Modularismus und Holismus in der Kognitionsforschung. Mouton de Gruyter, Berlin \& New York.

Nickles, Thomas 1980. Scientific discovery and the future of philosophy of science. In: Thomas Nickles (ed.): Scientific discovery, logic and rationality, 1-59. Reidel, Dordrecht.

Nickles, Thomas 2001. Discovery. In: W.H. Newton-Smith (ed.): A companion to the philosophy of science, 85-97. Blackwell, Malden MA \& Oxford.

Politzer, Guy - Gaëtan Bourmaud 2002. Deductive reasoning from uncertain conditionals. In: British Journal of Psychology 93:345-81.

Polya, George 1948. How to solve it. Princeton University Press, Princeton NJ.

Polya, George 1954. Patterns of plausible inference. Oxford University Press, Oxford.

Polya, George 1981. Mathematical discovery. John Wiley \& Sons, New York.

Putnam, Hilary 1962. What theories are not. In: Ernest Nagel-Patrick Suppes-Alfred Tarski (eds): Logic, methodology and philosophy of science, 240-52. Stanford University Press, Stanford CA. 
Rákosi, Csilla 2005. Nyelvészeti elméletek argumentációs szerkezetének elemzése [The analysis of the argumentation structure of linguistic theories]. Doctoral dissertation, University of Debrecen.

Rescher, Nicholas 1976. Plausible reasoning. Van Gorcum, Assen \& Amsterdam.

Rescher, Nicholas 1977. Methodological pragmatism. Blackwell, Cambridge MA \& Oxford.

Rescher, Nicholas 1979. Cognitive systematization. Blackwell, Cambridge MA \& Oxford.

Rescher, Nicholas 1987. How serious a fallacy is inconsistency? In: Argumentation 1: 303-316.

Rescher, Nicholas - Robert Brandom 1979. The logic of inconsistency. Blackwell, Cambridge MA \& Oxford.

Ringen, Jon D. 1975. Linguistic facts. A study of the empirical scientific status of transformational generative grammars. In: David Cohen - Jessica R. Wirth (eds): Testing linguistic hypotheses, 1-41. Hemisphere, Washington D.C.

Ruzsa, Imre 2000. Bevezetés a modern logikába [An introduction to modern logic]. Osiris Kiadó, Budapest.

Suppe, Federick 1977. The search for philosophic understanding of scientific theories. In: Frederick Suppe (ed.): The structure of scientific theories, 3-243. University of Urbana Press, Urbana IL.

Walton, Douglas N. 1991. Begging the question: Circular reasoning as a tactic of argumentation. Greenwood Press, New York \& Westport \& London.

Walton, Douglas N. 1992a. Plausible argument in everyday conversation. State University of New York Press, Albany.

Walton, Douglas N. 1992b. Rules for plausible reasoning. In: Informal Logic 1992/1 $33-51$.

Walton, Douglas N. 1996. Fallacies arising from ambiguity. Kluwer, Amsterdam.

Walton, Douglas N. 1997. Informal fallacies. In: Jonathan Dancy-Ernest Sosa (eds): A companion to epistemology, 212-6. Blackwell, Malden MA \& Oxford.

Walton, Douglas N. 2001. Abductive, presumptive and plausible arguments. In: Informal Logic 21 : 141-169.

Woods, John-Andrew Irvine-Douglas N. Walton 2000. Argument: Critical thinking, logic and the fallacies. Pearson, Toronto.

Woods, John-Douglas N. Walton 1989. Fallacies. Foris, Dordrecht.

Address of the authors: András Kertész-Csilla Rákosi

Research Group for Theoretical Linguistics

of the Hungarian Academy of Sciences

at the University of Debrecen

H-4010 Debrecen, Pf. 47.

Hungary

kert.esz@freemail.hu; rakosics@delfin.unideb.hu 